\title{
Classification of Software Engineering Documents Based on Artificial Immune Systems
}

\author{
Nada N. Saleem \\ Nada_N_S@uomosul.edu.iq \\ College of Computer Sciences and Mathematics \\ University of Mosul, Mosul, Iraq \\ Rasha Gh. Saeed
}

Received on: 05/03/2012

Accepted on: 28/06/2012

\begin{abstract}
Care about automated documents classification has increased since the appearance of the digital documents and the wide diffusion of Internet. In the 1990's, the computer performance has greatly improved and has led to the methods of machine learning to establish automated classifiers. These methods have achieved good speed and classification's accuracy and researchers still investigate in this field to accomplish more accuracy and less time. Artificial immunologic systems have shown high performance in such as data clustering and anomaly detection which can be ascribed to the nature of the immunologic system in protecting the body.

Some of the present methods and ways used in the training process of the document classification are time consuming and others have less accuracy rate concerned the classification of the related document as software engineering document classes For these reasons, this research deals with the study of Natural Immune System and using the dynamic process of the Innate Immune System work based on danger theory and Dendritic Cell (DC) technique in building Dendritic Cell Model (DCM) to classify Software Engineering documents as they comprise information related to developing the software systems, that makes it easy for the software engineer who works in maintenance.

DCM has high classification's speed and accuracy besides easy and flexible use by designing interfaces that makes it easy for the user to deal with the system. In order to improve the quality and the efficiency of DCM method, it was compared to one of the best and well-known methods of classification referred to as, Naive Bayes(NB). After conducting several experiments on a various group of software engineering documents, evaluations results have shown that the accuracy of the innate immunologic method (DCM) has reached (DCM) (95\%), whereas Naïve classification method has reached (90\%) with training and classification speed that doesn't exceed one minutes. This shows the feasibility of using the algorithms of AIS systems in the field of information recovery and documents classification. This system was built and programmed in Java language and was implemented under an operating system environment Microsoft Windows7.
\end{abstract}

Keyword: Artificial Immune System, danger theory, Dendritic Cell, Software Engineering Documents, document Classification.

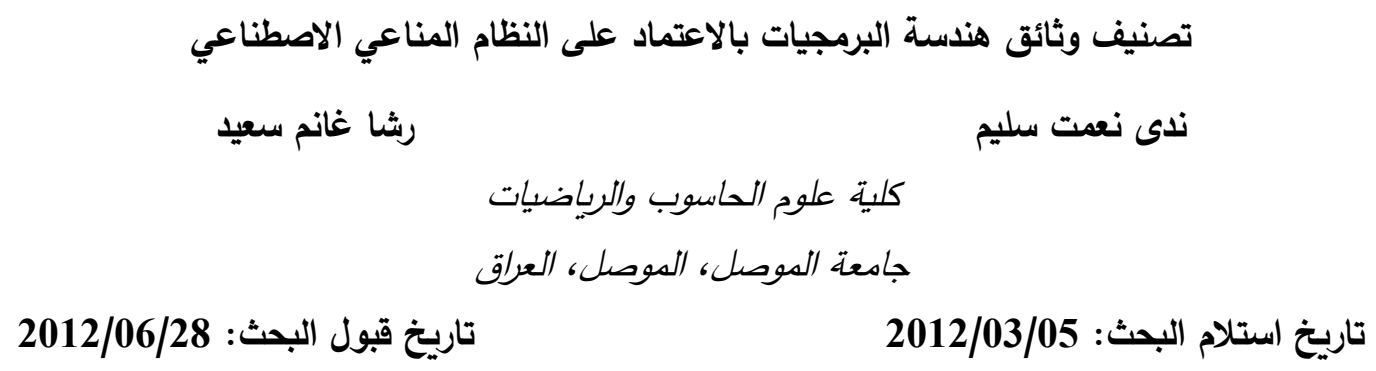




\section{الملخص}

تزايد الاهتمام بتصنيف الوثائق الآلي منذ ظهور الوثائق الرقمية والانتثـار الواسع للانترنيت. وفي التسعينات تحسن أداء الحاسوب بشكل كبير والذي قاد إلى استخدام طرائق تعليم الآلة لتكوين مصنفات آلية حقت دقة تصنيف وسرعة جيدة، وما زال الباحثون يبحثون في هذا الدجال لتحقيق دقة اكبر ووقت اقل. وقد أظهرت الأنظمة المناعية الاصطناعية أداءً عالياً في مهمة التصنيف مثل عنقدة البيانات و كثف ونف الثذوذ وذلك يعود لطبيعة النظام المناعي في حماية الجسم.

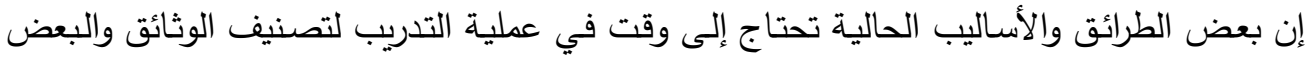
الآخر من الأساليب تكون دقة تصنيفها للوثائق قليلة فيما يتعلق بالوثائق المتقاربة الأصناف مثل أصناف وثائق هندسة البرمجيات, لذلك تتاول هذا البحث دراسة النظام المناعي الطبيعي واستخدام ديناميكية عمل النظام المناعي الفطري والاعتماد على نظريـة الخطر وتقنية الخلية التغصنية(DC) Dendritic Cell (DC في بناء أنموذج الخلية التغصنية Dendritic Cell Model (DCM) لتصنيف وثائق هندسة البرمجيات لما

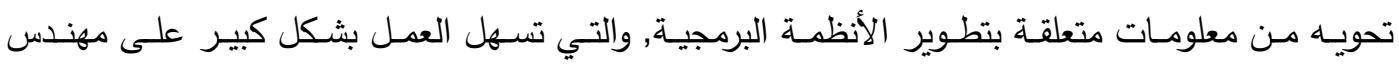
البرمجيات الذي يقوم بالتطوير والصيانة.

تمتلك طريقة التصنيف (DCM) دقة وسرعة عالية في التصنيف حتى فيما يتعلق بتصنيف الوثائق

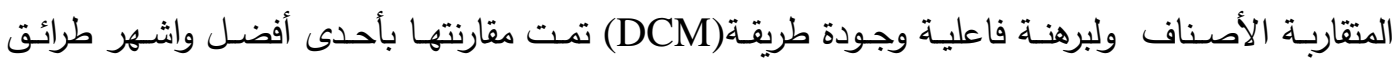
التصنيف المستخدمة وهي طريقة (Naïve Bayes (NB) وبعد إجراء التجارب على مجموعة متتوعة من لن وثائق هندسة البرمجيات ، أظهرت نتائج التقييم أن دقة طريقة تصنيف المناعة الفطرية(DCM (DCM) (95\%)، في حين أن دقة تصنيف (NB) (90\%), وبمعدل سرعة تدريب وتصنيف لا يتجاوز الدقيقة الواحدة, مما

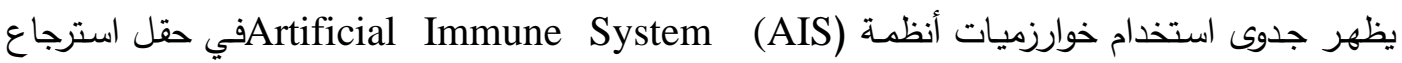
المعلومات وتصنيف الوثائق. تم بنـاء هذا الأنموذج وبرمجتهـ بلغـة جافـا وتتفيذه تحت بئئة نظام تثغيل مايكروسوفت ويندوز Microsoft windows7

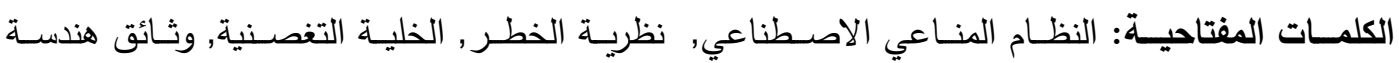
البرمجيات, تصنيف الوثائق

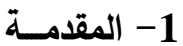

أصبح تصنيف الوثائق الآلي مجال بحث وتطبيق مهم منذ ظهور الوثائق الرقمية. إذ يعد تصنيف النص

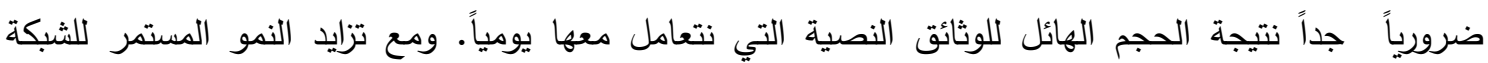
العنكبوتية (www)، فان تحديد المعلومات ذات العلاقة بالبحث أصبح عملية صعبة جداً. ولاسترجاع المعلومات بأقل وقت ممكن وبأعلى درجة من العلاقة جاء دور التصنيف الآلي إذ أن تصنيف الثبكة الآلي يساعد في استرجاع المعلومات بشكل أفضل [9]. استخدمت الوثائق لتوثيق أنواع متعددة من المعلومات ومنها المعلومات

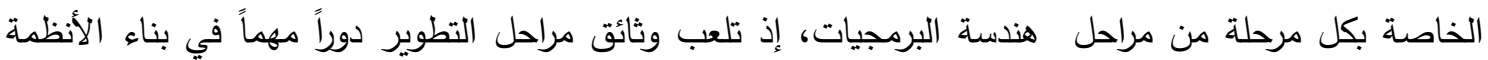
البرمجية، ويشكل التوثيق وسيلة لتقديم الرؤية ضمن عملية البرمجيات، ويعد دور الاتصال أساسيا لتطوير 
البرمجيات[22]. كما ويعد امتلاك مخزن للمعرفة من العوامل المهمة في نجاح أي نوع من الأعمال التقنية الكبيرة

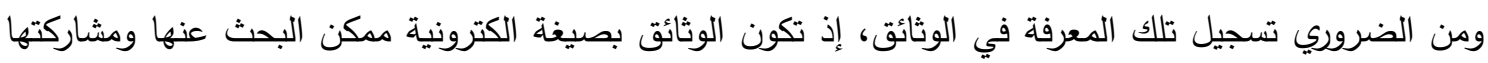

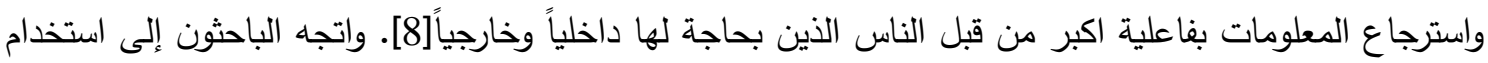
المفاهيم الذكائية لحل مشكلات استرجاع المعلومات والتصنيف وقد حققوا انجازات في ذلك، ومن المفاهيم الحديثة في حقل الذكاء الاصطناعي هي الأنظمة المناعية الاصطناعية والتي تم استخدامها في البحث وبناء مصنف لتصنيف الوثائق لمراحل هندسة البرمجيات.

\section{2- Literature Review الدراسات السابقة}

حاول الباحثون في السنوات الماضية إيجاد حلول واقتراحات كثيرة لتصنيف الوثائق بطرائق سهلة، سريعة، ذات كفاءة عالية وكلفة قليلة، وذلك من خلال استخدام تقنيات تعليم الآلّة التي كان لها إمكانية في تحسين أتئي أداء المصنفات، ومن هذه البحوث:

1. في عام 1997 قدم الباحثان Billsus و Pazzani ونثاً عن عدد من خوارزميات التعلم المختلفة. واختبار اداء ودقة مصنف Naïve Bayes (NB) ، الدجاور الاقرب، اشجار القرار والثبكات العصبية ووجد ان اداء مصنف NB الافضل بصورة عامـة. وايضـاً بين دور اختيار الخواص في زيـادة دقة المصنف وتقليل خطأ التصنيف [32].

2. بحثاً عن الة دعم المتجه Joachims بـ كام 1998 قدم الباحث بوصفها طريقة لتصنيف الوثائق إذ اثبتت هذه الطريقة كفاءتها بالتصنيف الا انها تعاني من التعقيد، ويقع

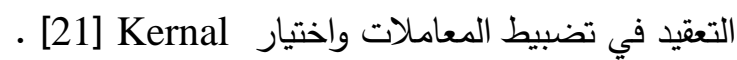
3. في عام 1999 قدم الباحثان Cohen و و Singer بحثاً لطرائق التعليم لتصنيف النص واستخدما أشجار القرار

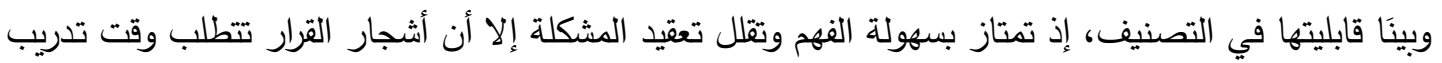

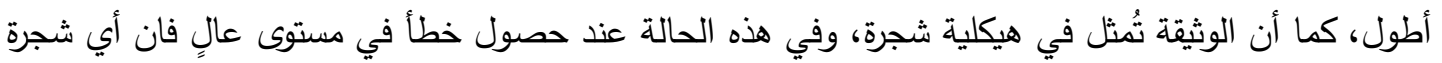
فرعية ستكون خاطئة][3]. 4. في عام 2002 قدم الباحث Sebastiani بحثاً عن طرائق التصنيف واستخدام الشبكة العصبية وامكانيتها في

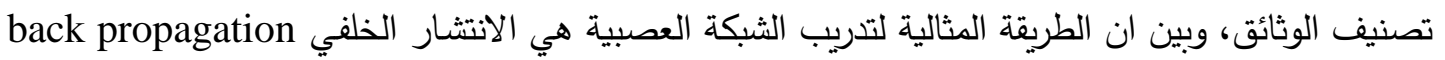
إذ عند حصول خطأ بالتصنيف يتم ارجاع الخطأ ونشره ثم يتم تغيير المعاملات للشبكة وبالتالي يقل الخطأ. قدمت الشبكة العصبية نتائج جيدة الا ان تدريب الشبكة يكون بطيئًا [35]. 5. في عام 2002 قدم الباحثان Zuben و Decastro بحثاً يتناول التصنيف باستخدام خوارزمية الانتقاء النسيلي، وذلك بتوليد كرات التمييز الاصـطناعية)Artificial Recognition Balls(ARBs والتتي تستجيب للمستضدات (مجموعة متجهات التدريب)، الكرات الأكثر استجابة تُخزن في مخزن خلايا الذاكرة وتُكون أداة التصنيف، استخدمت الطفرة في الخوارزمية مما جعل ARBs غير مماثلة لمتجهات التدريب من جهة، ومن جهة أخرى تكون متثابهة كفاية لتدريب متجهات أخرى. بين البحث قدرة نظام المناعة على التعلم وكفاءته في التصنيف، وأن عدد خلايا الذاكرة المتكونة عادة يكون نصف عدد خلايه خلايا التدريب[ة]. 
6. في عام 2005 قدم الباحثون Paab و Nurnberger و Hotho بحثاً عن استخدام مصنف المجاور الأقرب

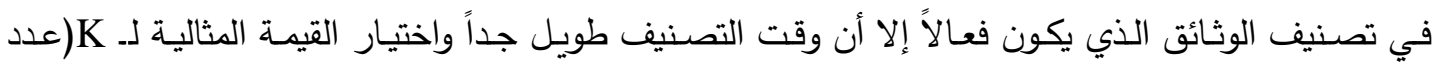

المجاورات) تعد قضية صعبة، إذ أن اختيار قيمة واحدة لـ K تلائم كل التطبيقات امراً مستحيلاً [17]. 7. في عام 2007 قدم الباحثان Romero و مino طريقة لاستخلاص الكلمات ذات الدلالة من الوثائق النصية بالاعتماد على نظام المناعة، إذ تعتمد على خلفية رياضية والتي تُعرِف بطريقة قياسية: التفاعل بين الأجسام

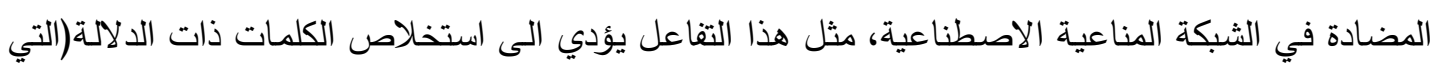

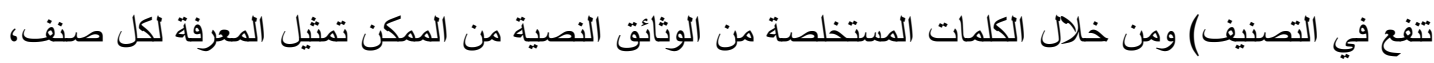

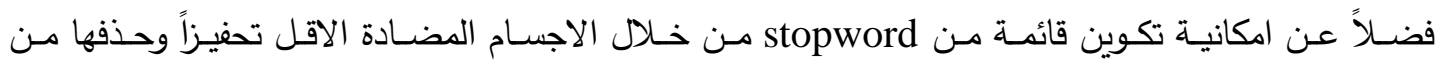
الثبكة(حذف الكلمات ذات التحفيز القليل من الشبكة)][33ن.

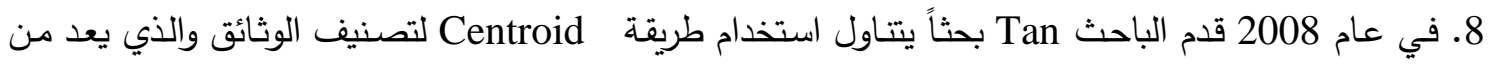
الطرائق الارشادية الثائعة في التصنيف والمعروف ببساطته قدم هذا الباحث تحسيناً على المصنف باضافة

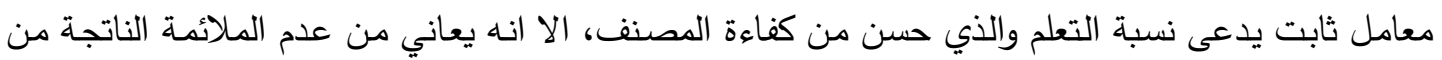

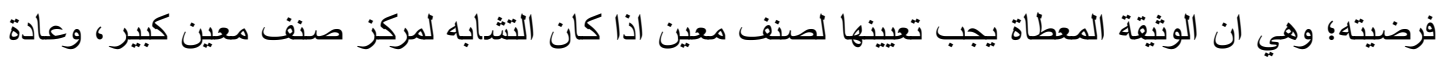
يكون هذا الافتراض غير صحيح في الحالات العملية[37].

\section{Natural Immune System (NIS)}

لقد تمت دراسة جهاز المناعة عند الإنسان بصورة جيدة لما يزيد عن المائة عام ولكن لا يزال هذا الجهاز لم يفهم بشكل كامل. فجهاز المناعة هو نظام دفاعي تطور ليحمي المضيف من الكائنات الممرضـة Pathogens

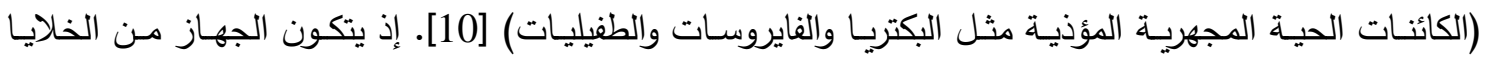
المتخصصة المتتوعة والتي تتتشر وتراقب الجسم وكذلك جزيئات خلويـة إضـافية متتوعة وتنظيمات مناعية تعمل على توفير بيئة للخلايا المناعية لتتفاعل وتتمو وتستجيب[18]. تتشأ الخلايا المناعية في نخاع العظم والتوتة وعند نضوجها تهاجر إلى الأنسجة متنقلة عبر الأوعية الدموية واللمفاوية. إن الوظيفة الرئيسية لتلك الخلايا هي تمييز وجود العناصر الغريبة في الجسم وتعمل على الاستجابة التهابه لتتخلص منها أو لتقضي على تأثير الداخلين الأجانب[24]. تدعى المواد التي يمكن أن تحفز استجابات معينة في

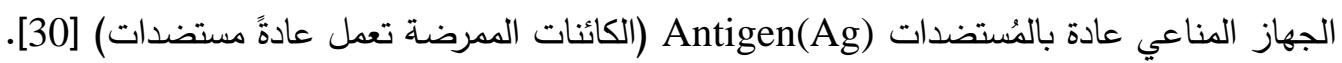
إن نظام المناعة الطبيعي يتكون من خط دفاعي ذي طبقتين تعرفان على أنهما جهاز المناعة الفطري وجهاز

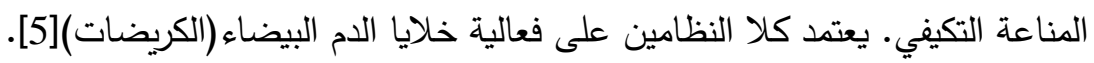

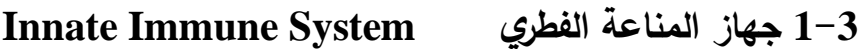
جهاز المناعة الفطري (غير المكتسب) هو الخط الأول للدفاع الذي يعمل على تقديم استجابة فورية ولكنها

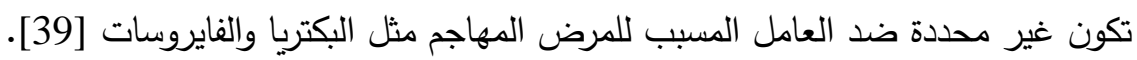

\section{Adaptive Immune System}

يشار الى جهاز المناعة التكيفي أيضا بانه جهاز المناعة المكتسبة، حيث تطلق عليه هذه التسمية لانه مسؤول عن تخصيص دفاع للكائن الحي المضيف الذي سيواجه الخطر وذلك بالاعتماد على العامل المررض لهاء 
المحدد،على عكس جهاز المناعة الفطري، يوجد جهاز المناعة المكتسبة بالفقريّات فقط (الحيوانات ذات العمود

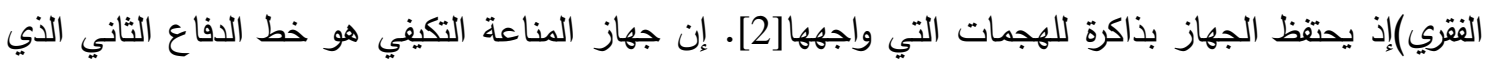
يتوسط استجابة محددة ومتأخرة [39].

يتم تتظيم جهاز المناعة المكتسبة حول صنفين من الخلايا:الخلايالتائية T-Cell والخلايالبائية B-Cell ان صنف خلايا جهاز المناعة الفطري هي اكثر تعددا، وبضمنها الخلايا القاتلة Naturalkiller (NK) الخلايا

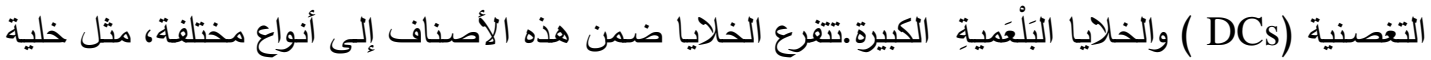

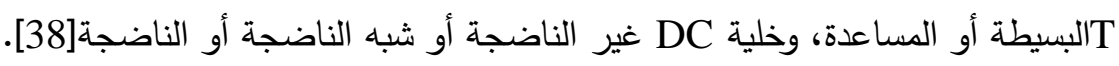

\section{Natural Immune System Theories}

NIS ن ن ن

توجد نظريات مختلفة عن دراسة علم المناعة فيما يتعلق بالسلوك الوظيفي والتنظيمي مابين الخلايا اللمفاوية عند الاستجابة إلى المُستضد المهاجم الذي تواجهه، تضم هذه النظريات[7]:

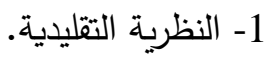

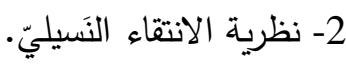
3- نظرية الشبكة.

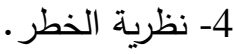

\section{Classical Theory} 4-4 النظرية التقليدية

إن النظريـة التقليدية لجهاز المناعة هي إن جهاز المناعة يميز مابين ما هو طبيعي (ذاتي) وغريب (غير

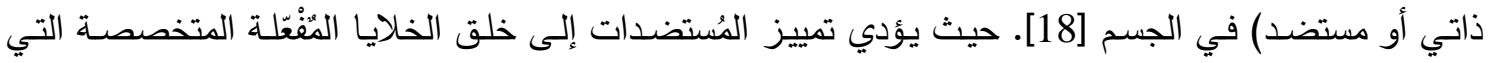
تعمل على خمول وتدمير هذه المُستضدات.

\section{Clonal Selection Theory} 2-4 20 نظرية الانتقاء النَسيليّ

يصف مبدأ الانتقاء النَسيليّ الصفات الأساسية لاستجابة المناعة لمحفزات المُستضد، الفكرة الأساسية لهذه

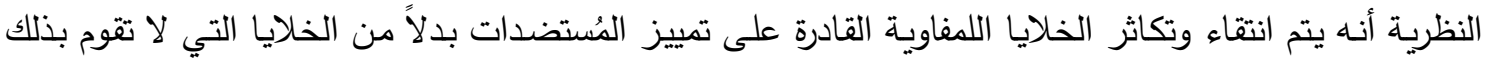
وتتمايز إلى الخلايا المُستَفعِلة Effector Cells]

\section{Immune Network Theory} 3-4 نظرية شبكة المناعة

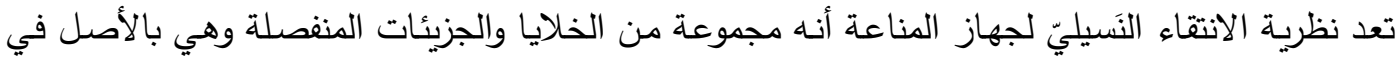
استراحة ويتم إثارتها فقط بواسطة تحفيز مستضد غريب. تقدم شبكة المناعـة نظريـة مختلفة فكرياً لكيفية تفاعل

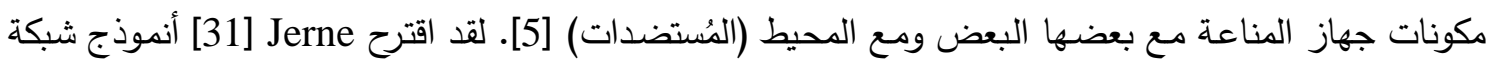

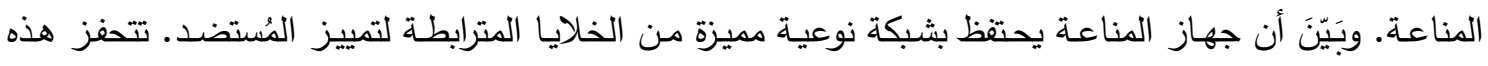
الخلايا وتثبط إحداها الأُخرى بطريقة معينة تؤدي إلى استقرار الثبكة.

\section{Danger Theory}

4-4 نظرية الخطر

قدمَت عالمة المناعة Polly Matzinger في عام 1994 نظرية الخطر [27]. ذكرت أن جهاز المناعة يُيُسيطر عليه بواسطة اكتشاف الضرر الذي يحصل في الجسم، وليس بواسطة اكتثاف تراكيب المُستضد كما وأن 
الإشارات لا تأتي من مصادر خارجية المنشا، ولكنها داخلية وتقوم بانتاجها خلايا النسيج نفسها. إن هذه الإشارات

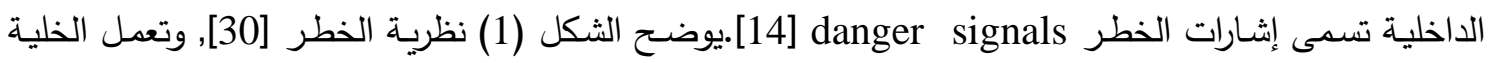

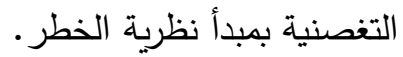

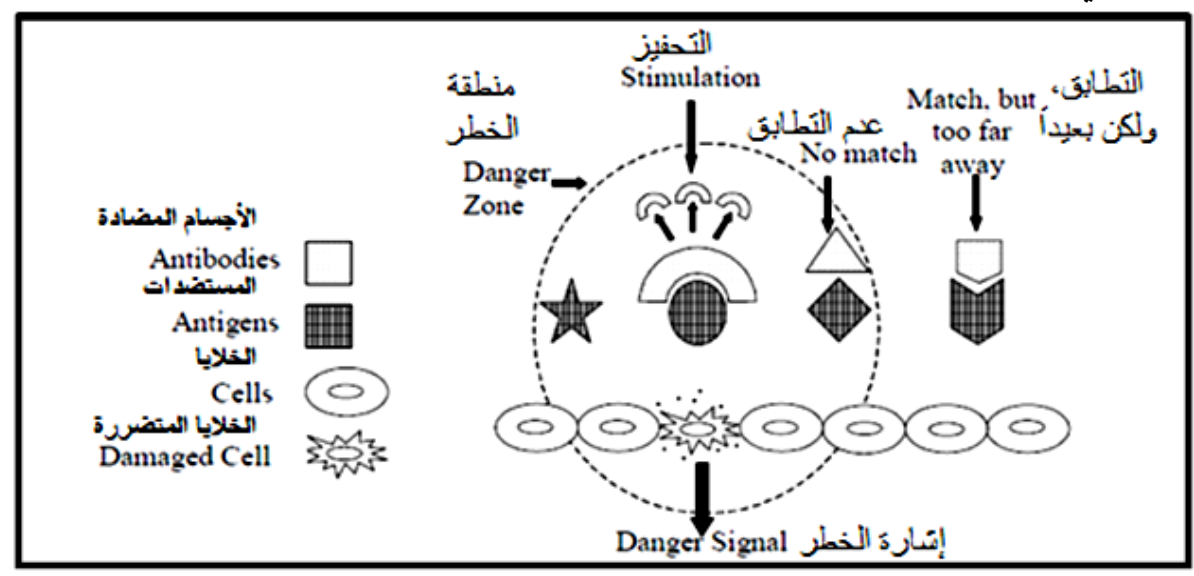

الثكل (1) أنموذج نظرية الخطر]30]

Dendritic Cell (DC)

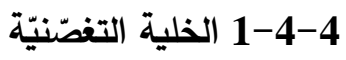

تمتلك خلايا جهاز المناعة الفطرية القابلية على اكتشاف العوامل المسببة للمرض بواسطة الخلايا البَلْعَميةِ. يجهز جهاز المناعة الفطرية معلومات عن كل اتصال سابق مع الداخلين الغرباء أكثر من المعلومات التي يوفرها

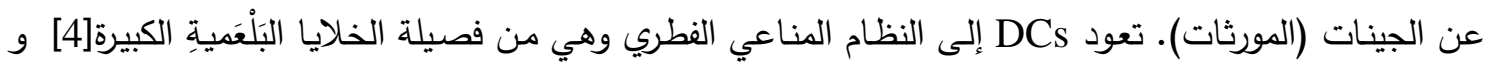
تعمل على شكل واجهة ما بين جهازي المناعة الفطري والتكيفي، وتوجد الخلية التغصّنيّة في ثنلاث حالات مختلفة

$$
\begin{aligned}
& \text { كما موضح في الثكل (2): } \\
& \text { 1- غير ناضجة. } \\
& \text { 2- ناضجة (كثفت عن جزيئات تعرضت للنخر). }
\end{aligned}
$$$$
\text { 3- شبه ناضجة (كثفت عن جزيئات تعرضت للموت الطبيعي) }
$$

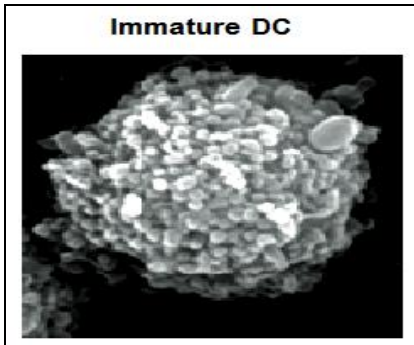

خلبِة تفضتنبِة غير ناضجة

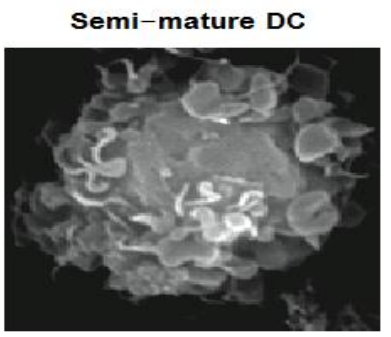

خلبِة تَفصنيَّة شُبه ناضجة

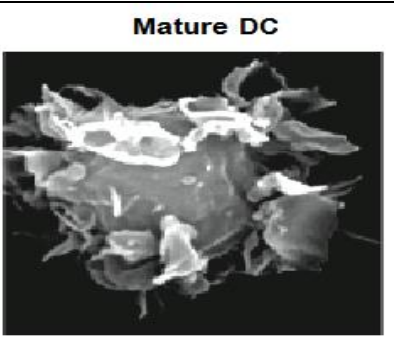

خلبِة تغصنيَّة ناضجة

الثكل (2) حالات الخلية التغصّنيّة]

كل DC هيذ خلية غير ناضجة ووفقاً لتجميع الإشارات التي يتم استقبالها يمكن أن تتغير حالتها [26].

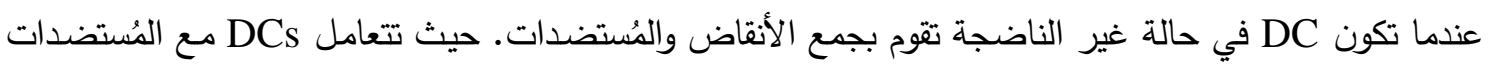
من خلال المُستقبلات الموجودة في سطح الخلية، والتي تتحس الإنس الإشارات المختلفة. بعد عملية المعالجة، تعتمد

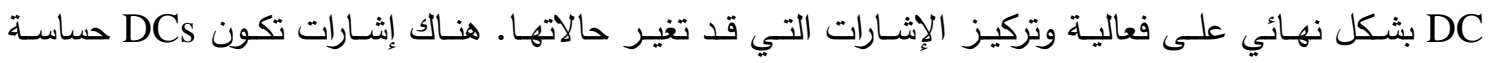


1- الأنماط الجزيئية المرتبطة بالعامل المسبب للمرض (PAMP)

Pathogenic Associated Molecular patterns(PAMPs)

Danger Signals( DSs)

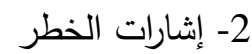

Safe Signals( SSs)

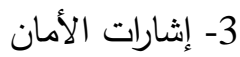

Inflammation Signals (ISs)

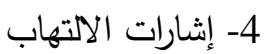

إن الصفات الأساسية للخلية التغصّنيّة هي: التهاب:

1- التقسيم إلى جزيئات : تجهز هذه الصفة المنطقتين المنفصلتين اللتين تتجز فيهما DCs عمليتي الاختبار والتحليل. تحصل عملية إدخال الإثارات وتجميع المُستضد في "النسيج"، وهو المحيط الذي تقوم DCs فيه بالمراقبة. وعند نضوجها تهاجر إلى مركز المعالجة، ويسمى عقدة اللمف. بينما في عقدة اللمف، تقدم مستضداً مرتبطاً مع إشارات السياق، والتي تفسر وتترجم إلى استجابة مناعية. وبهذا تبقى الخلايا

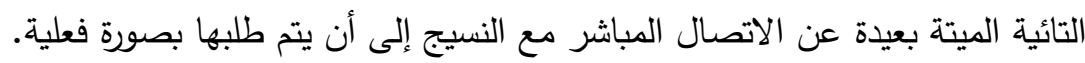

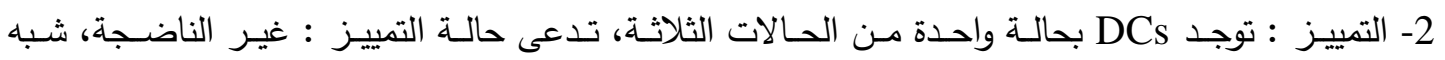
الناضجة، والناضجة. تحصل الانتقالات إلى شبه الناضجة والناضجة من خلال تمييز DC غير الناضجة.

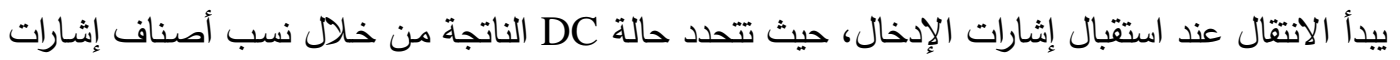
الإدخال التي استقبلتها الخلية غير الناضجة. تسيطر الحالة النهائية للتمييز على سياق تقديم المُستضد

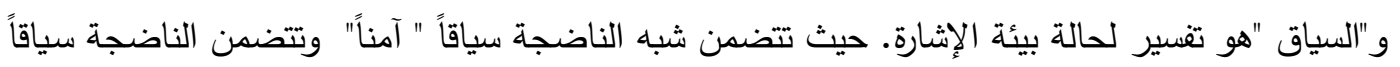
" خطراً "، كما موضح في الثكل (3). وبهذا يستخدم جهاز المناعة آلية القرار لتحديد نوع الاستجابة[15].

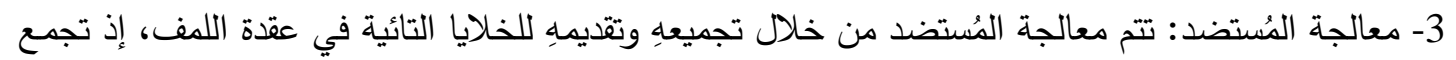

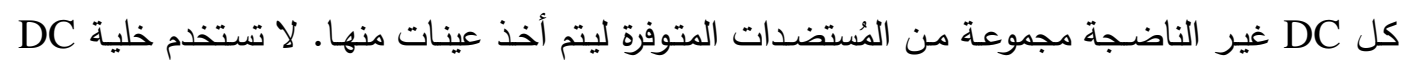
تطابق النمط لتركيب المُستضد [1].

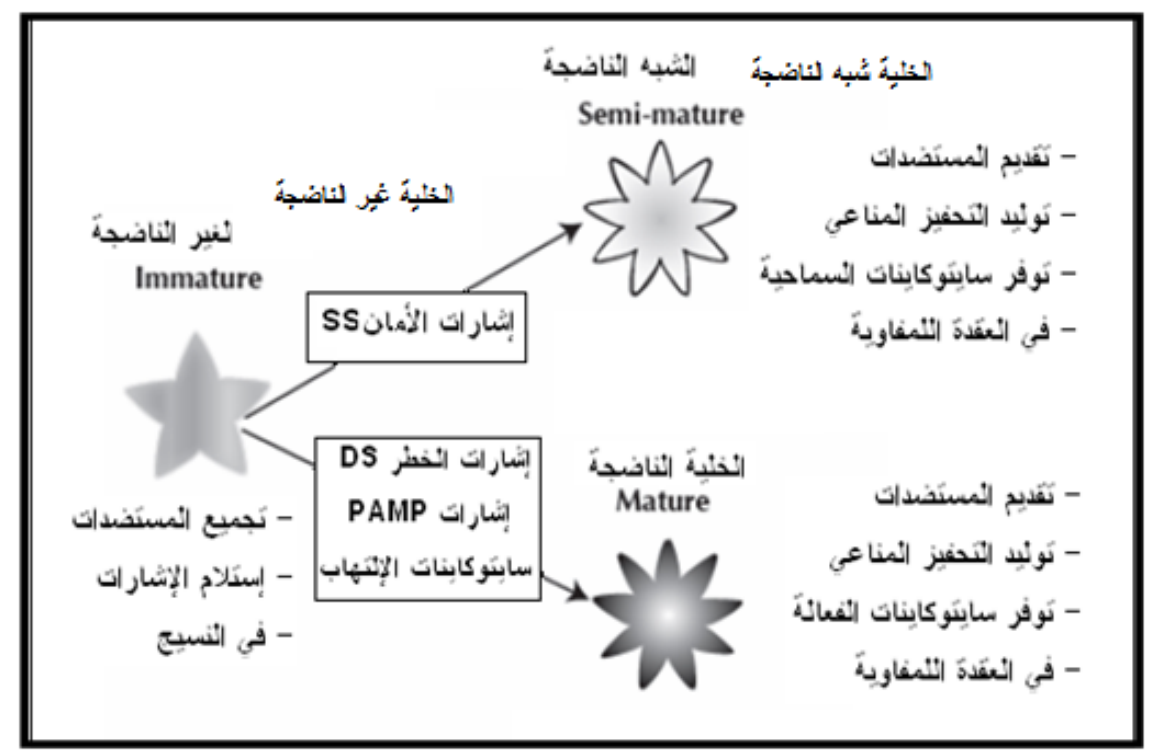

الشكل (3) أنموذج مجرد لتمييز DCs مبيناً التحول مابين الحالات والإشارات المسؤولة عن التحولات. إن

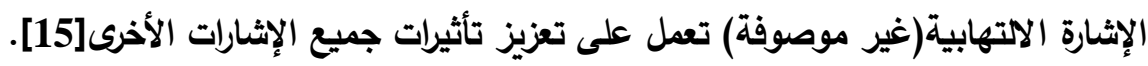


4- معالجـة الإثـارة : تقوم الخلايـا التغصـنية بمعالجـة الإثـارة، وتكون حساسـة للتغير في تركيز -الجزيئات

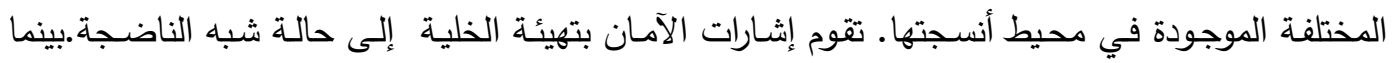
تكون إشارات الخطر و PAMPs مسؤولة عن نضوج الخلية إلى حالة النضـج الكاملة[40]. تتولد إشارات الإخراج بتركيز يتتاسب مع إثارات الإدخال المستلمة ويوضح الثنكل (4) التفاعل مات ما بين الإشارات.

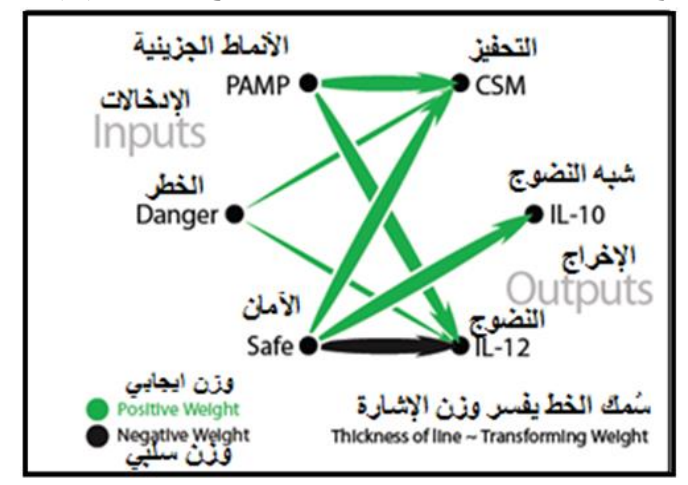

الثكل (4) أنموذج مجرد لمعاملة DCs للإثشارات]ن

تتـت DCs ثلاثاً من إثـارات الإخراج كما في الشكل (4) وذلك نتيجة لتعرضـها لإشـارات الإدخال من

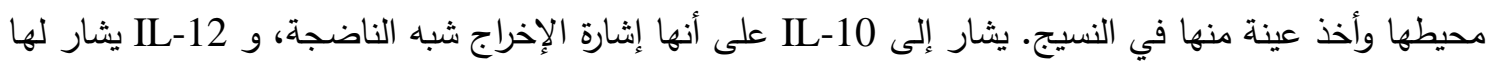

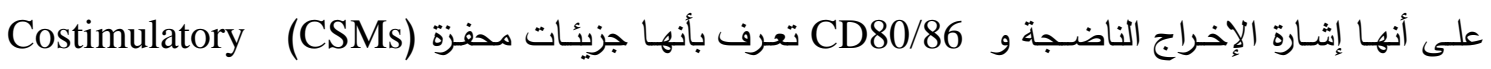

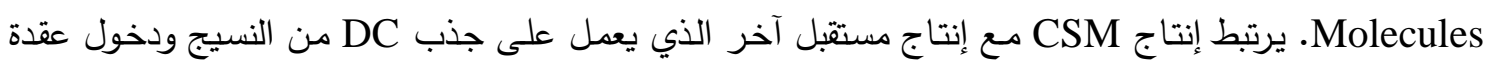

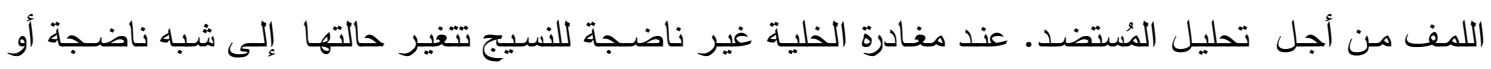

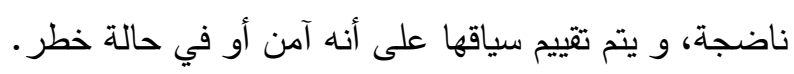
يتم تحديد محيط DCs عن طريق تحديد أي إثارة من إثارتي الإخراج اكبر عند تمثيل المُستضد. إذا كانت إثارة

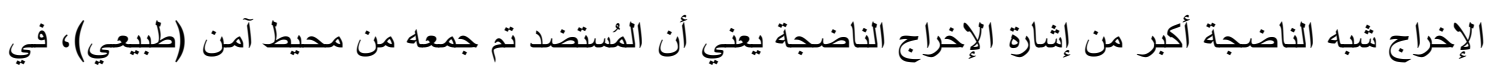
حين إذا كانت إثارة الإخراج الناضجة أكبر يعني أن المُستضد تم جمعه من محيط غير آمن (شاذ). يتم تمرير

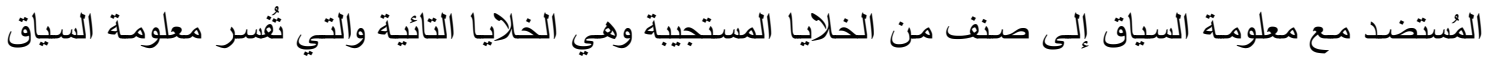
المُقدمة لها بوساطة سكان DC المحلية [16،20، 11، 11، 12].

\section{Artificial Immune System (AIS) 5ظام المناعة الاصطناعي}

AIS

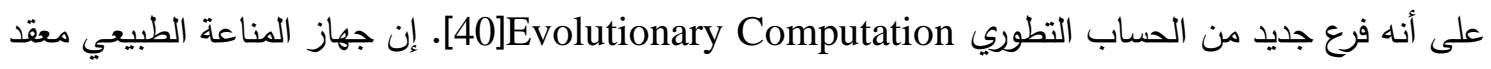

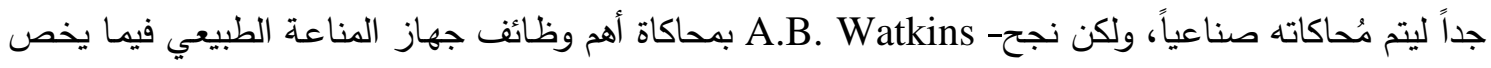
تمييز الأنماط. إن نظام المناعة الاصطناعي، هو مجموعة من خوارزميات التصنيف الذكية، التي تستخدم آلية دفاع المناعة الطبيعية لأغراض تتنية، قادرة على التكيف والتعلم. لذلك انتشر هذا الففهوم في تطبيقات تقنية عديدة

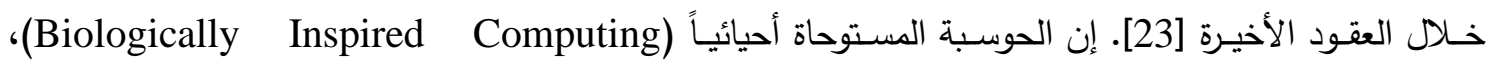
وخصوصـاً أنظمـة المناعـة الاصطناعية (AIS) هي حل واعد لتطوير أدوات دفاعية مكيفة ومؤتمتـة للتهديدات

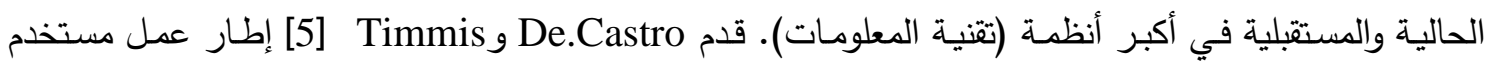

بصورة أكثر شيوعاً في هندسة AIS، والموضح في الثنكل(5). 


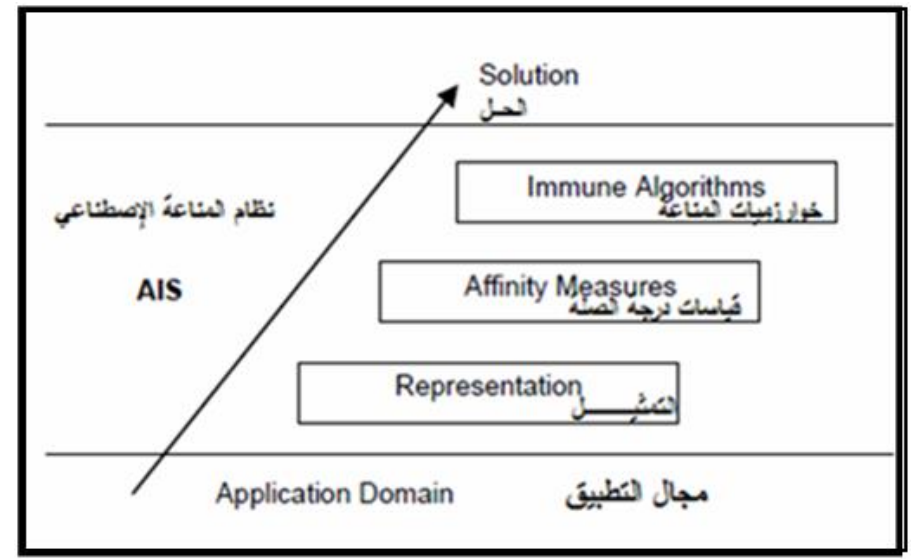

[5] AIS الشكل (5) طبقات إطار عمل

يتضمن إطار العمل ثنلاث خطوات مستقلة بشكل نسبي في بناء (AIS). إن أسـاس كل نظام هو مجال

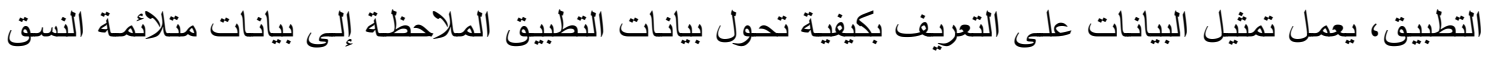

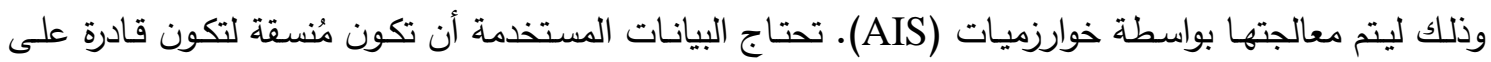
قياس درجة الصلة في مجال تمثيل البيانات، إن قياس درجة الصلة هو في صلب التصنيف والتمييز بواسطة خوارزميات (AIS) (على الاقل هذا صحيح بالنسبة لخوارزميات (AIS) التكيفية) [5].

\section{Denderitic Cell Model(DCM)}

6- مصنف أنموذج الخلية التغصنية

تم في هذا البحث تطوير أنموذج التصنيف DCM والذي يعتمد على نظام المناعة الفطري المتمثل بالخلايا التغصنية DC ، إن تقنيـة الخليـة التغصنية تقوم بعمليـة التصنيف بالاعتمـاد على البيانـات المدخلـة والإثـارات

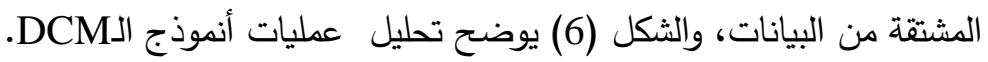

\section{Description of DCM} 1-6 وصف أنموذج الخلية التغصنية يتكون الأنموذج من وحدتين (التهيئة والتصنيف). * وحدة التهيئة : وفيها يتم معالجة الوثائق النصية وتكوين القاموس والذي يماثل الخلية التغصنية، باستخدام الخطوات التالية: خطوة 1: قراءة الوثائق (المستضد) من نوع HTML و PDF.

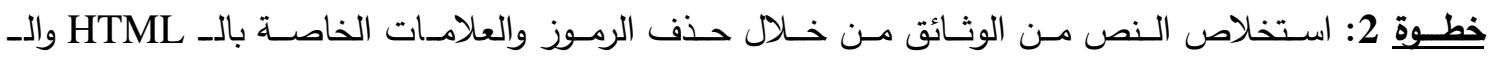
.JavaScript خطـوة 3: استخلاص الكلمـات المفيدة وتكوين (متجـه الخـواص) وذلك بإزالـة التكـرار وإزالـة الكلمـات المستبعدة (stopwords) والرموز عديمة الأهمية.

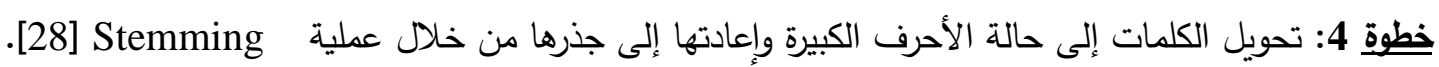

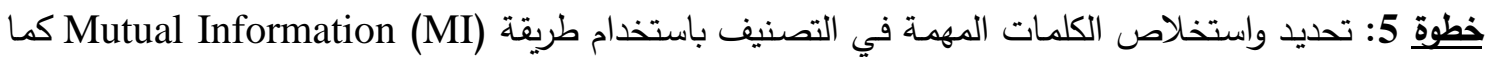
مبين في المعادلة رقم(1)[29]. 


$$
\mathrm{MI}(\mathrm{t}, \mathrm{c})=\log \frac{\mathrm{P}(\mathrm{c}, \mathrm{t})}{\mathrm{P}(\mathrm{t}) \cdot \mathrm{P}(\mathrm{c})}
$$

حيث أن: t : t : الكلمة c c c الصنف t عـد الوثـائق التـي تحـوي الكلمـــ

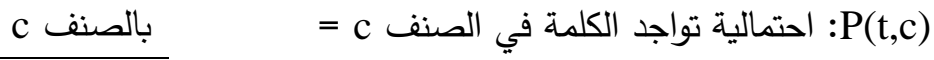

$$
\begin{aligned}
& \text { ع عدد الوثائق التي تعود للصنف }
\end{aligned}
$$

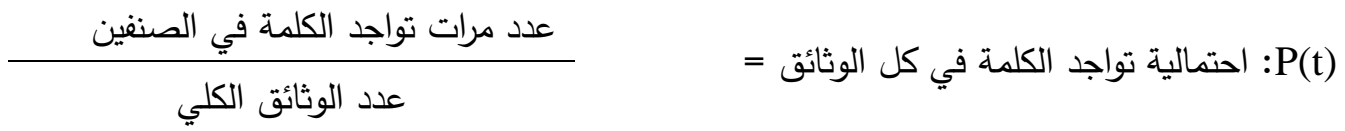

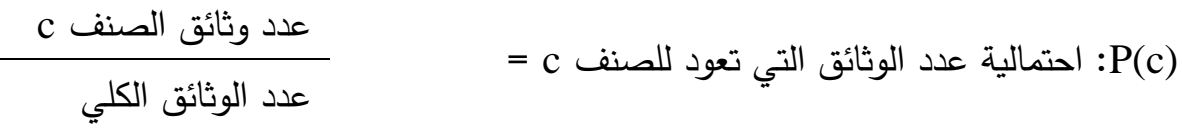

$$
\begin{aligned}
& \text { خطوة 6: خزن القاموس (DC) بعد التكوين. }
\end{aligned}
$$

* وحدة التصنيف :- وفيها يتم نمذجة تطبيق عمل الخلية التغصنية. تتكون وحدة التصنيف من مرحلتين؛ مرحلة النسيج (إدخال الوثائق المراد تصنيفها وحساب الإخراج التراكمي) ، ومرحلة عقدة اللدف (تحليل الوثائق وتصنيفها). عند إدخال وثائق الإختبار في مرحلة النسيج يتم تطبيق الخطوات الآتية : خطوة1 : قراءة وثيقة الاختبار ومعالجتها بإزالة الرموز العديمة الأهمية و استخلاص النص وتكوين قائمة بالكلمات (متجه الخواص).

خطوة2 : تحويل قائمة الكلمات( متجه الخواص) المتكونة في الخطوة 1 بهيئة متجهات باستخدام التمثيل الثنائي. خطوة3: اشتقاق الإشـارات من الوثائق المدخلة بالاعتمـاد على ميكانيكية عمل الخلية التغصنية ونظريـة الخطر للنظام المناعي الموضحة في الفقرة 1-4-4. 
class Business Process Model

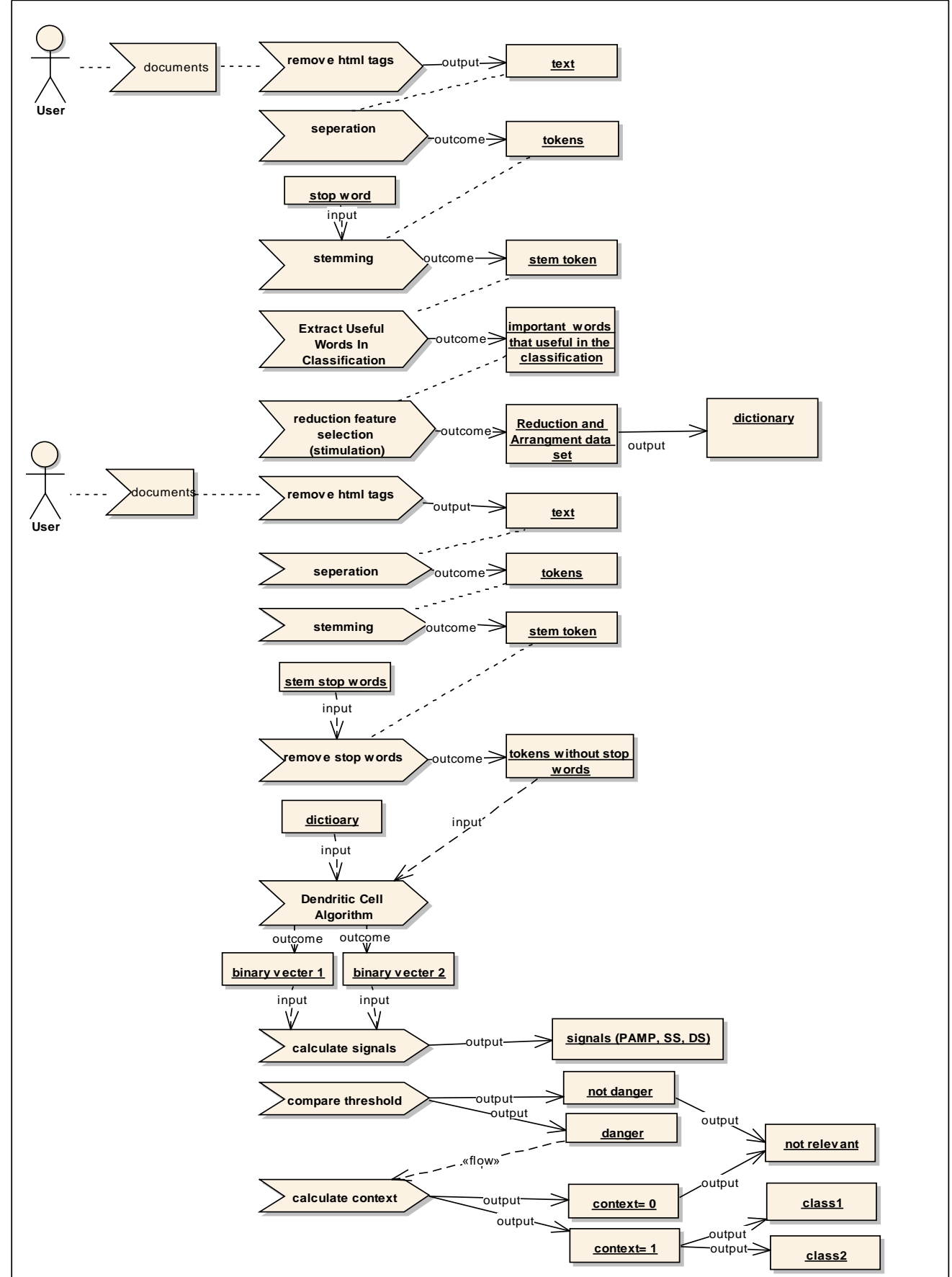

\section{الشكل (6) أنموذج عمليات DCM}

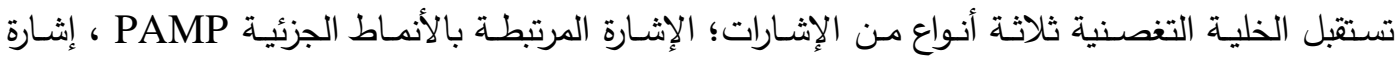
الخطر DS وإشارة الأمان SS وكل واحدة من هذه الإشارات يجب إثتقاقها وتمثيلها إذ يتم التصنيف بموجبها. تم إقتراح وإثتقاق قيم الإشارات الثلاث كما يأتي : PAMP مجموع عدد الواحدات في المتجه إذ كلما زادت قيمة PAMP زادت : زادت قوة الإشارة. $\operatorname{PAMP}\left(\operatorname{Doc}_{\mathrm{j}}\right)=\sum_{\mathrm{i}=0}^{\mathrm{n}} \operatorname{Doc}_{\mathrm{j}}(\mathrm{i}) \quad$ if $\operatorname{Doc}_{\mathrm{j}}(\mathrm{i}) \neq 0$ 
n = n تمثل طول المتجه.

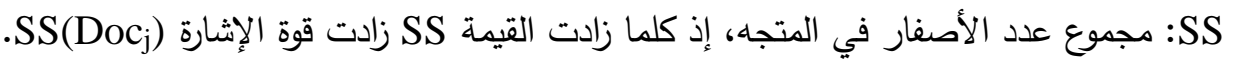

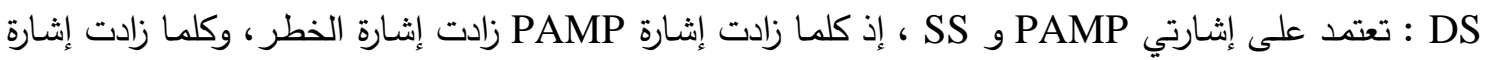
SS $\operatorname{DS}\left(\operatorname{Doc}_{\mathrm{j}}\right)=\operatorname{PAMP}\left(\operatorname{Doc}_{\mathrm{j}}\right) / \mathrm{SS}\left(\operatorname{Doc}_{\mathrm{j}}\right)$

بعد تمثيل الوثائق والإشارات المشتقة منها يتم تطبيق تقنية DC.

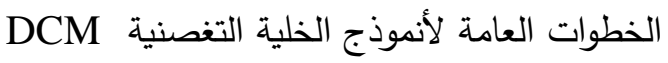
المدخلات : المستضدات (الوثائق) والإشارات. المخرجات : قيم سياق المستضدات.

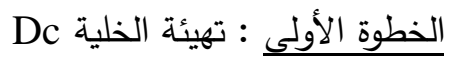
الخطوة الثانية : طالما قيمة الإخراج CSM* للخلية تكون أقل من قيمة حد العتبة لهجرة الخلية Migth يتم عمل الخطوات التالية للخلية الحالية وإلا يعد المستضد مصدر خطر لإحراج 1.2 أخذ المستضد وخزنه في الخلية الحالية. 2.2 حساب قيم الإثارات (DS, SS, PAMP).

3.2 حساب قيم المخرجات التراكمية للخلية بإستخدام المعادلة (4).

الخطوة الثالثة : إنتقال الخلية من النسيج إلى العقدة اللمفاوية لأجل التحليل.

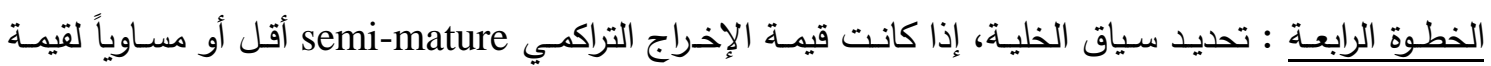
الإخراج التراكمي mature فإن (سياق الخلية = 1). وإلا فإن (سياق الخلية = 0. 0). الخطوة الخامسة : إستقبال وثيقة جديدة.

* Costimulatory يـتم حسـاب قيم المخرجـات التراكميـة للخليـة في الخطوة الثانيـة مـن الخوارزميـة بإسدتخدام معادلـة الجمـع Output $_{n}=\left[\left(\right.\right.$ PAMP $\left.\left._{\mathrm{n}} * \mathrm{PAMP}_{\mathrm{wn}}\right)+\left(\mathrm{DS}_{\mathrm{n}} * \mathrm{DS}_{\mathrm{wn}}\right)+\left(\mathrm{SS}_{\mathrm{n}}+\mathrm{SS}_{\mathrm{wn}}\right)\right] \ldots$ (4)

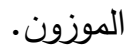
حيث أن: PAMPwn : الوزن المحدد لإثارة الأنماط الجزئية المُمرضة (PAMP).

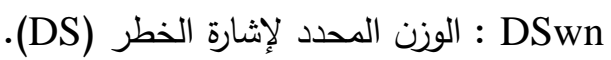

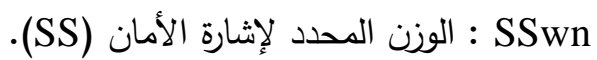
3=n SS $S_{n}, D_{n}$, PAMP Output $0=$ CSM.

Output $1=$ Semimature.

Output 2= Mature.

تم إثتقاق الأوزان المستخدمة في المعادلة (4) والموضحة في الجدول (1) عن طريق عدة تجارب أجريت

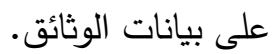


جدول(1) أوزان معادلة الجمع التراكمي

\begin{tabular}{|c|c|c|c|}
\hline & PAMP & Danger Singed(DS) & Safe Singed (SS) \\
& S0 & S1 & 2 \\
\hline CSM (O0) & 2 & 1 & 3 \\
\hline Semi-mature (O1) & 0 & 0 & -1 \\
\hline Mature (O2) & 100 & 75 & S2) \\
\hline
\end{tabular}

بعد إنتقال الخلية إلى عقدة اللمف يبدأ دورها في حساب قيمة السياق لها ، خلال الخطوة الرابعة ضمن أنموذج DCM. إذ يتم مقارنة قيم الإثارات المخرجة من الخلية. والمخطط الانسيابي في الشكل (7) يوضح كيفية

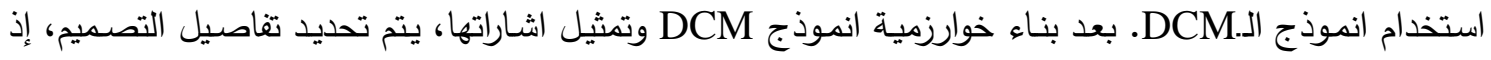

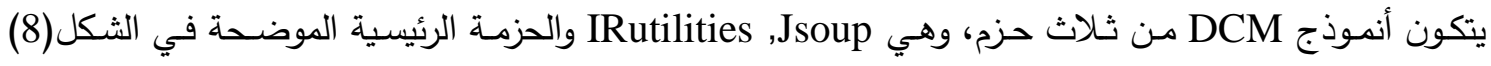
وتحوي على كل صنفيات (Classes) البرنامج من تهيئة، اختبار واستدعاء الحزم الأخرى.

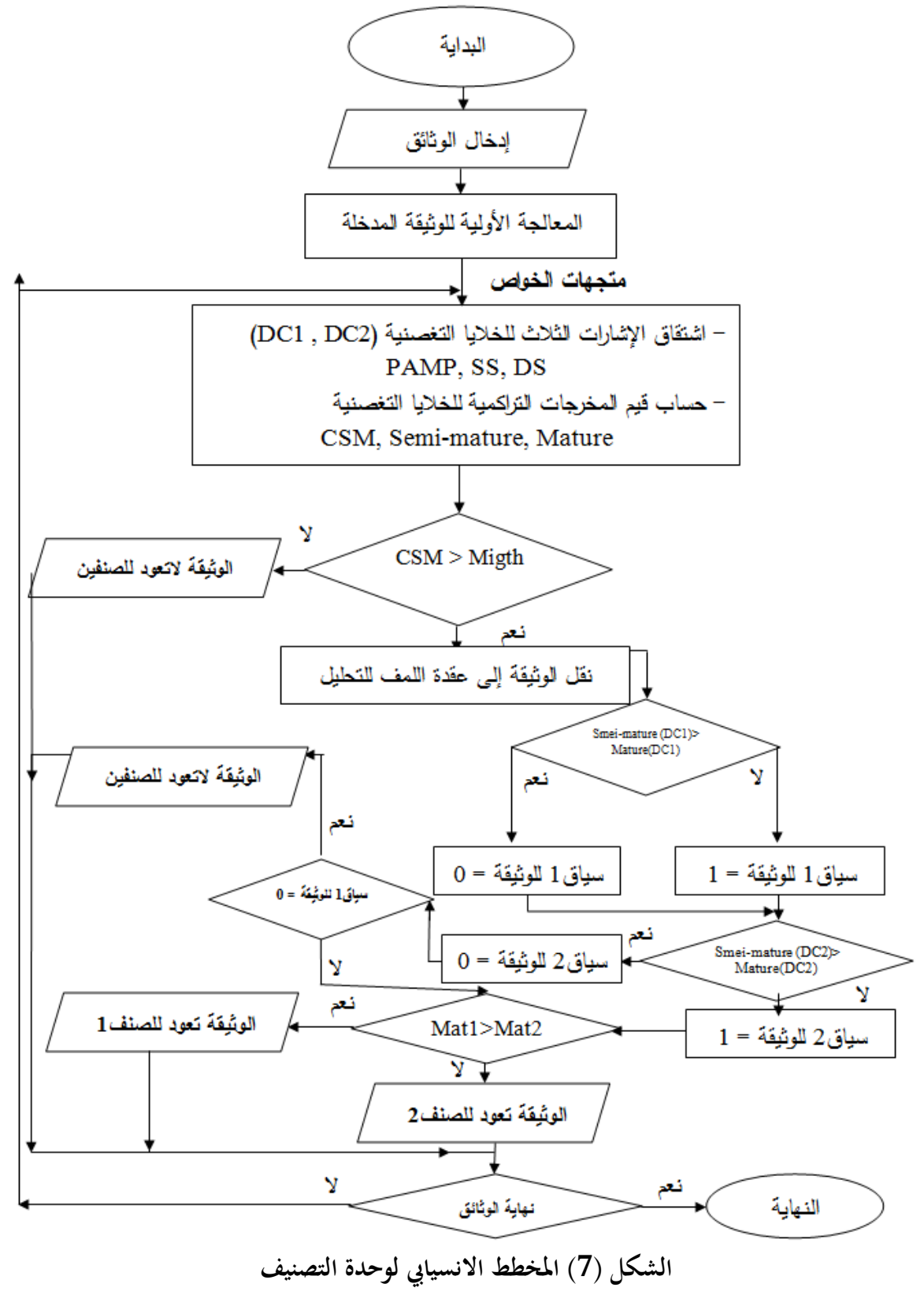




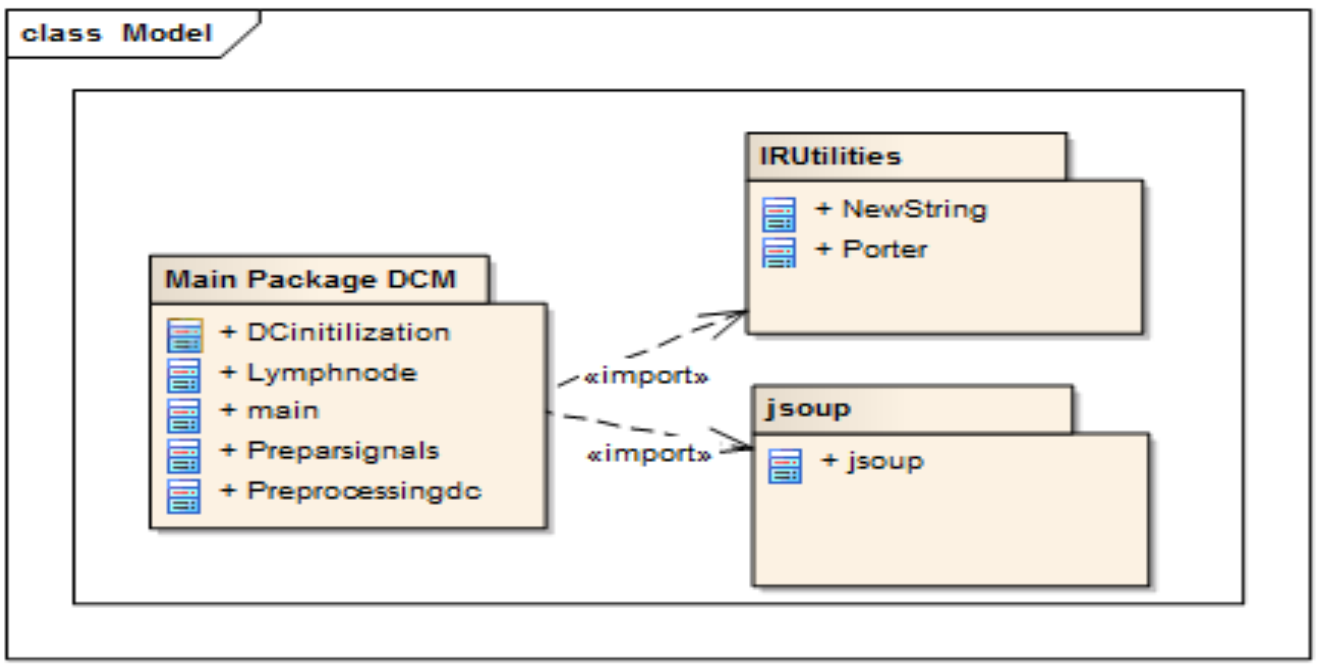

\section{الثكل (8) مخطط الصنفيات للحزم الثلاثة لأنموذج DCM}

بعدها يتم تحديد الدوال والمتغيرات الخاصة بكل صنف باستخدام مخطط الصنفيات الموضح في الثكل (9) ثم يتم تحديد الترتيب الزمني للصنفيات حسب التسلسل الزمني لاستدعائهم باستخدام المخطط التسلسلي الموضح في الثكل (10). (10)

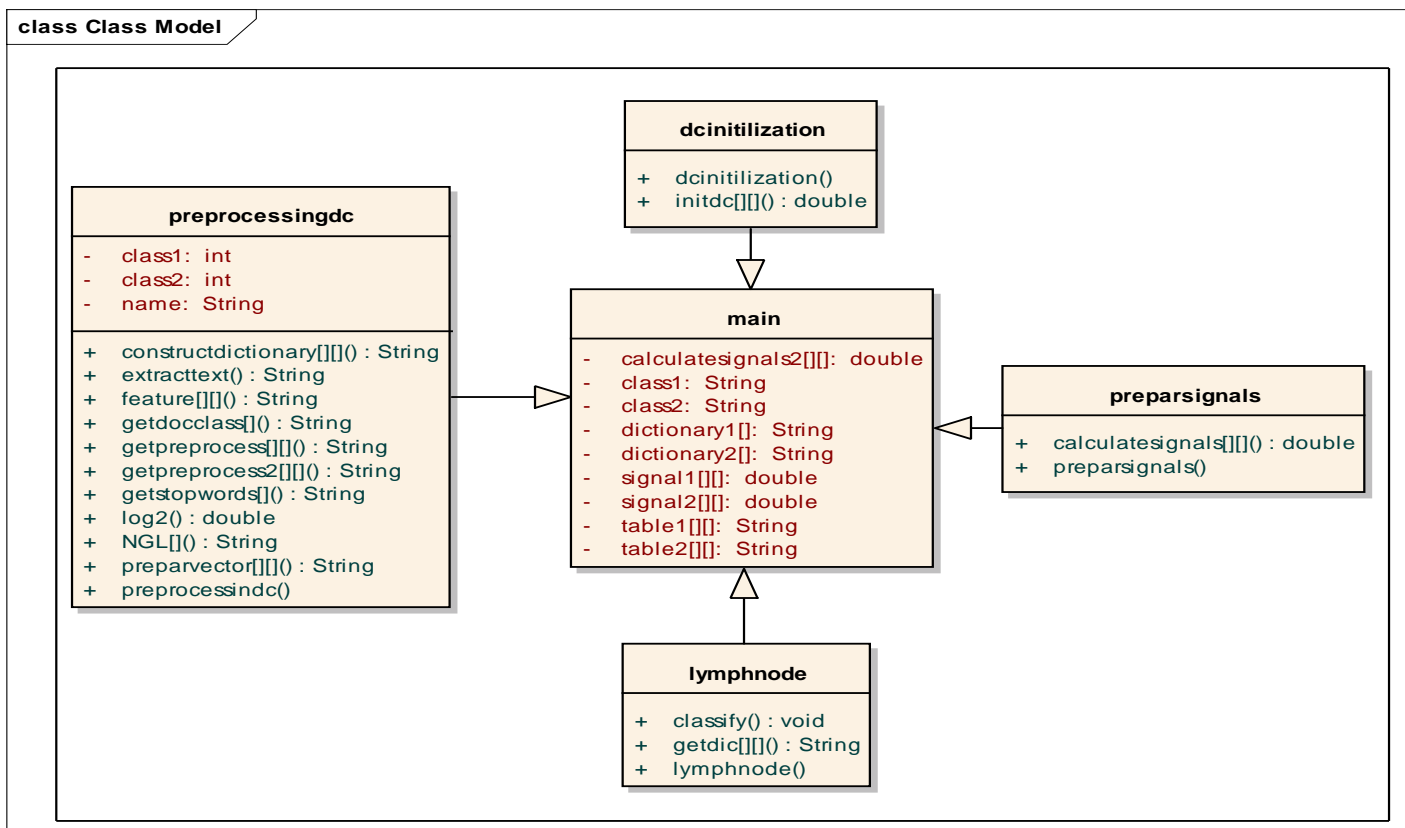

الثكل (9) مخطط صنفيات الحزمة الرئيسية لأنموذج DCM 


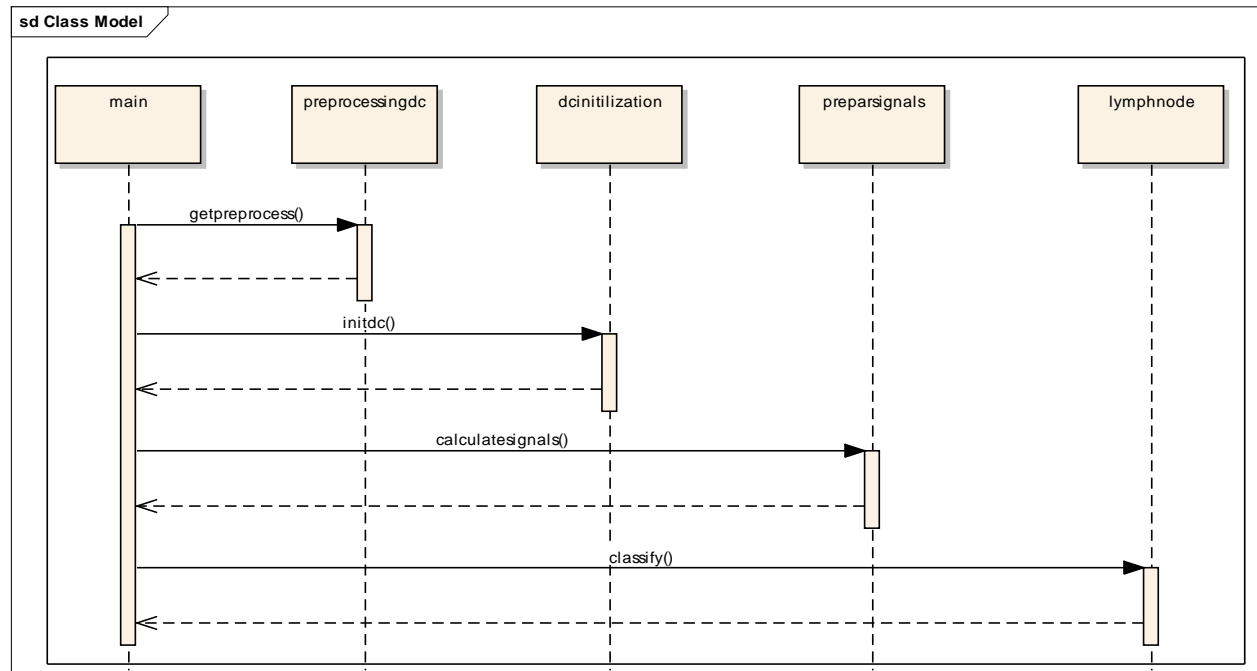

الثكل (10) المخطط التسلسلي لأنموذج DCM

Initialization \& Implementation of DCM Model DCM

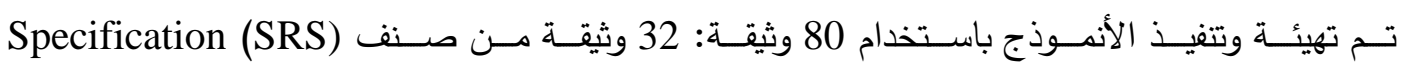
Software Test Description (STD) و 48 وثيقة من صنف بأ Software Requirements

يوجد صيغ عديدة لخزن الوثائق ومن اشهرها (HTML)، وعند تهيئة النظام باستخدام هذه الوثائق يتم

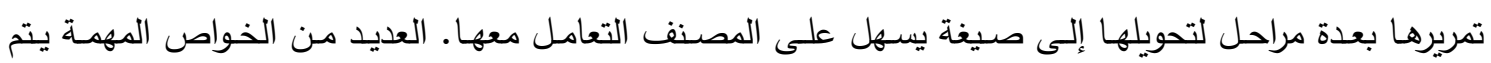
الحصول عليها خلال مرحلة التهيئة، والخطوة الأساسية في هذه المرحلة هي تحديد الخواص التي ستستخدم في لئي

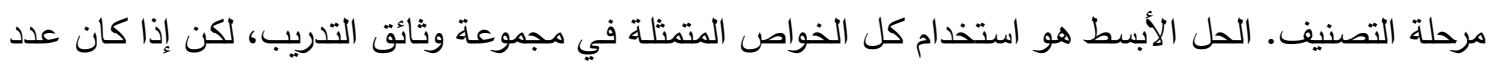

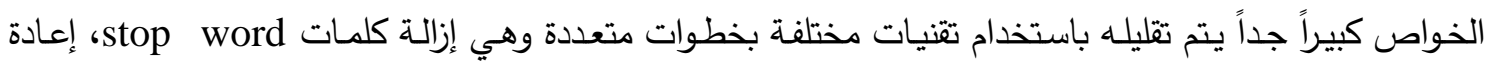

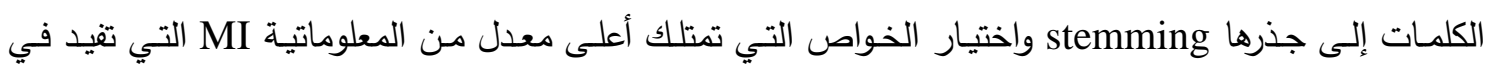
التصنيف وخزنها في القاموس، والثكل(11) يوضح تأثير كل من هذه التقنيات على تقليل عدد الخواص.

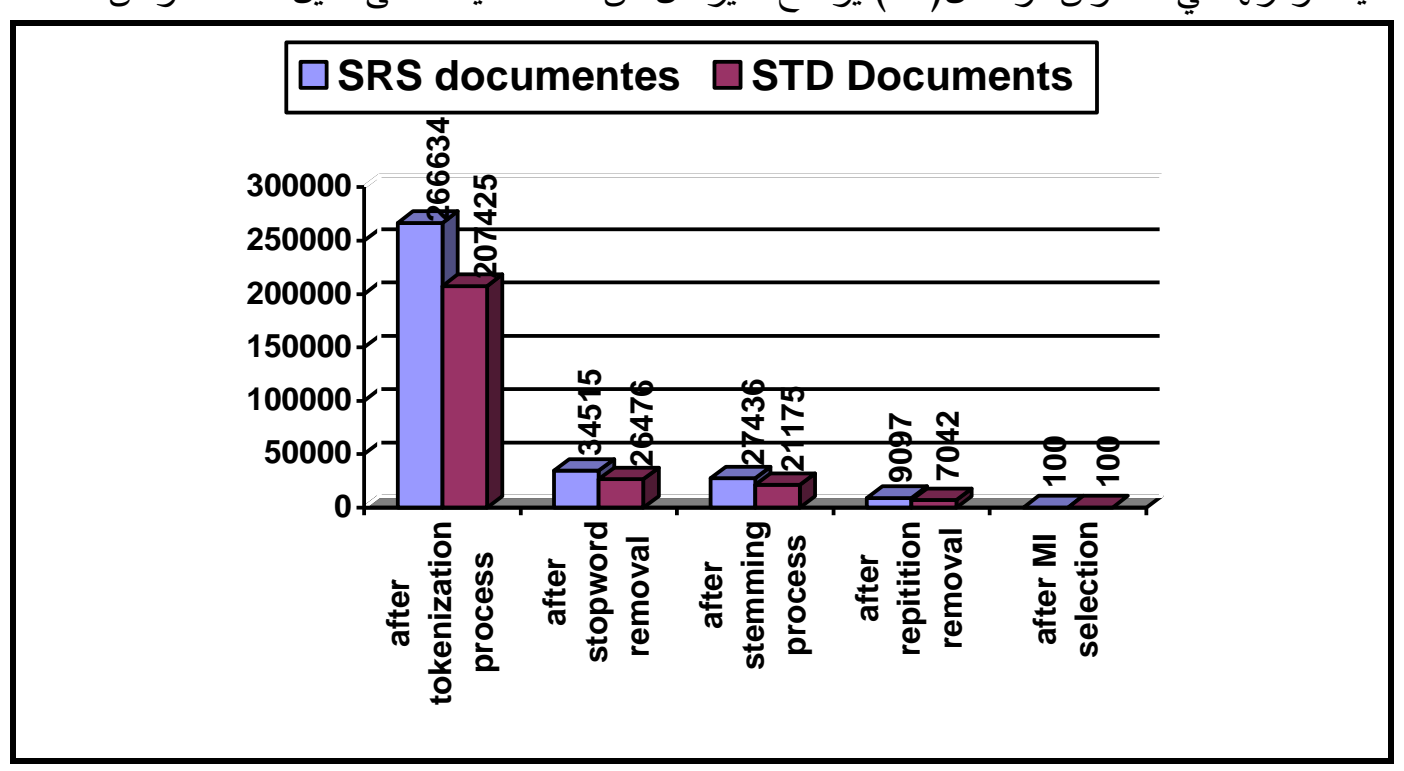


الثكل (11) تأثير العمليات المختلفة على حجم متجه الخواص

Testing of Model and Results

3-6 - - - اختبار الأنموذج ونتائجه

تم اختبار الأنموذج DCM من خلال إدخال مجموعة من وثائق مراحل هندسة البرمجيات والتي تم تحميلها

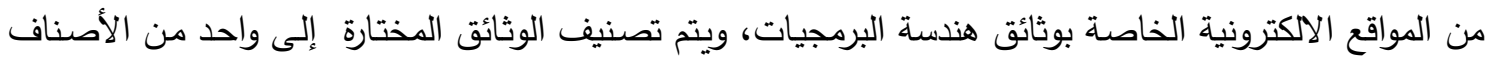
التالية :

$$
\begin{aligned}
& \text { 1- الصنف الأول SRS. } \\
& \text { 2- الصنف الثانيٍ } \\
& \text { 3-3 لا تعود للصنفين. }
\end{aligned}
$$

تم إجراء الاختبار على مجاميع باعداد مختلفة من الوثائق، الجداول والأشكال التالية توضـح نتائج اختبار تصنيف وثائق هندسة البرمجيات. يوضـح الجدول (2) والثكل(12) نتائج دقة تصنيف وثائق التدريب من وثائق .NB و DCM لمصنفات SWE

الجدول(2) نتائج تصنيف وثائق التدريب (80) وثيقة

\begin{tabular}{|c|c|c|c|c|c|c|}
\hline Model & 250 & 500 & 750 & 1000 & 1500 & 2000 \\
\hline DCM & 97.5 & 97.5 & 95.0 & 95.0 & 91.25 & 92.5 \\
\hline NB & 96.25 & 96.25 & 93.75 & 93.75 & 90.0 & 91.25 \\
\hline
\end{tabular}

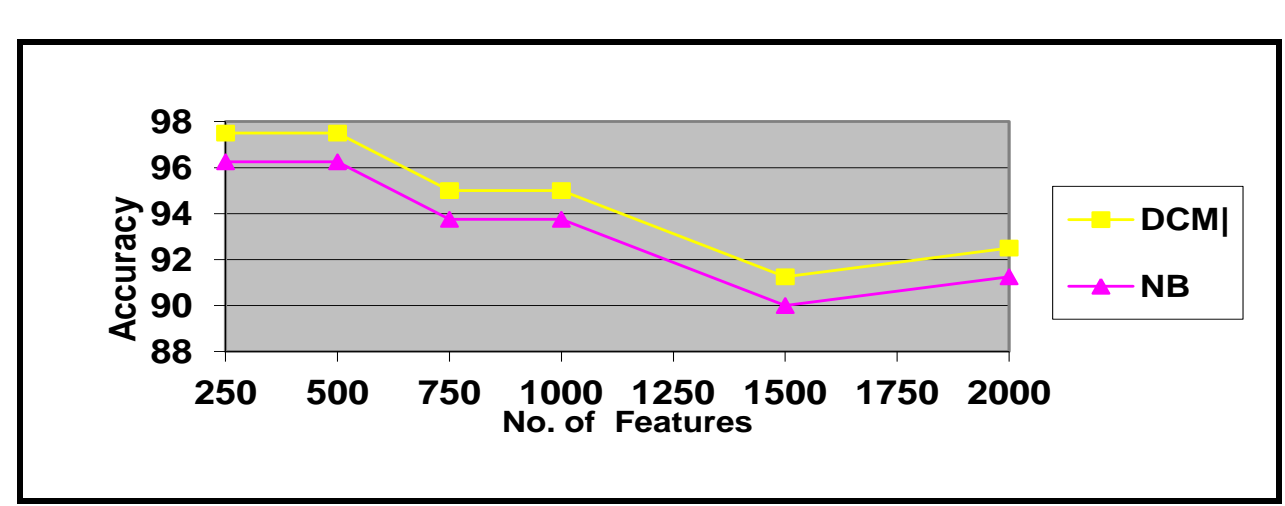

الثكل (12) دقة المصنفات لوثائق التدريب

يوضـح الجدول (3) والثـكل(13) نتائج دقـة تصـنيف (40) وثيقـة اختبار مـن وثائق SWE للمصـنفات .NB و DCM

الجدول(3) دقة تصنيف (40) وثيقة اختبار

\begin{tabular}{|c|c|c|c|c|c|c|}
\hline Model Features & 250 & 500 & 750 & 1000 & 1500 & 2000 \\
\hline DCM & 95 & 95 & 92.5 & 92.5 & 92.5 & 92.5 \\
\hline NB & 90 & 87.5 & 87.5 & 87.5 & 87.5 & 90 \\
\hline
\end{tabular}




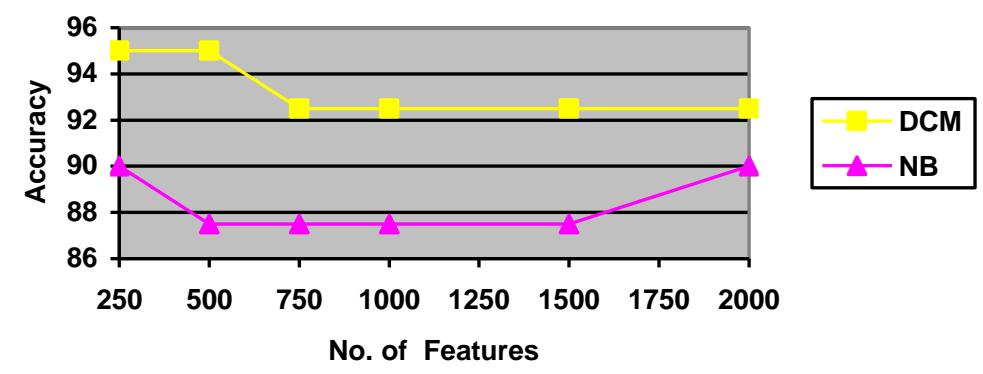

الشكل(13) دقة المصنفات لوثائق الاختبار

يوضح الجدول (4) والثكل(14) نتائج دقة التصنيف لمجاميع وثائق التدريب والاختبار الكلي والبالغ (120)

الجدول(4) دقة تصنيف الوثائق الكلية (التدريب والاختبار) (120) وثيقة

\begin{tabular}{|c|c|c|c|c|c|c|}
\hline Model & 250 & 500 & 750 & 1000 & 1500 & 2000 \\
\hline DCM & 95.0 & 95.0 & 94.17 & 91.67 & 92.5 & 90.0 \\
\hline NB & 94.17 & 95.0 & 92.5 & 90.0 & 87.5 & 90.0 \\
\hline
\end{tabular}

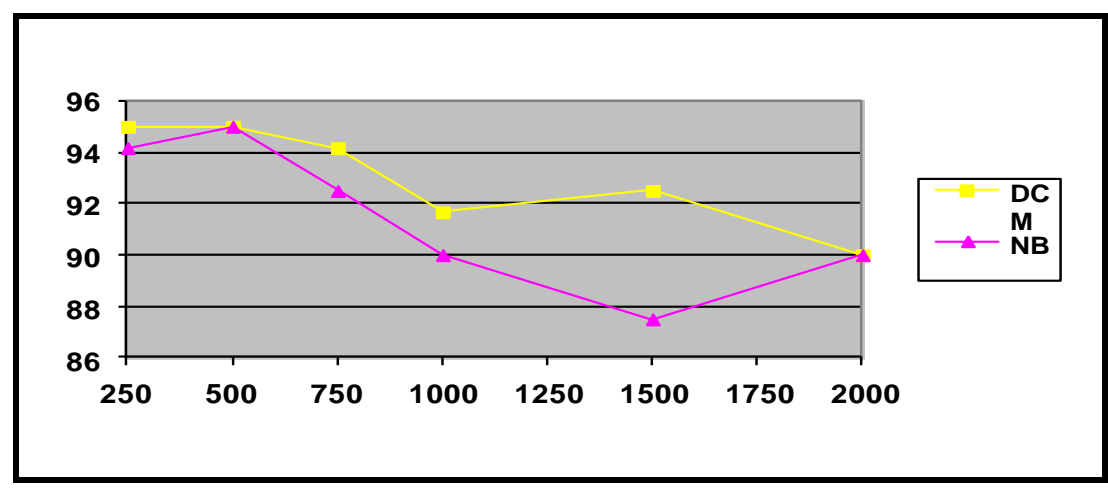

الثكل(14) دقة المصنفات لمجموعة الوثائق الكلية

يتبـين من قيم دقـة المصنفات الموضـحة في الجداول (2),(3),(4) أنـه كلمـا زاد عدد الخواص قلت دقـة المصنف لوثائق هندسة البرمجيات، ويقدم عدد الخواص 250 و 500 أفضل دقة تتبؤ بالنسبة للمصنفات. يعد المصنف DCM المعتمد على تقنيات المناعة الفطريـة افضل من مصنف NB، اذ يمتلك دقة تتبؤ عالية تصل إلى 97.5\% إذا تدرب على الوثائق مسبقاً و95\% لوثائق الاختبار ومجموعة الوثائق الكلية من تدريب واختبار • إن

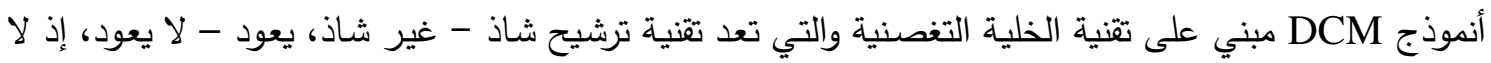

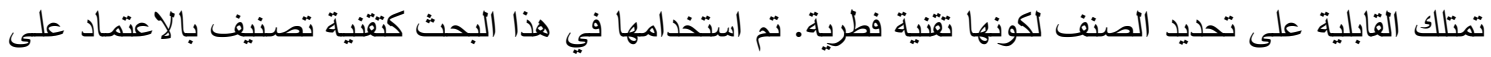

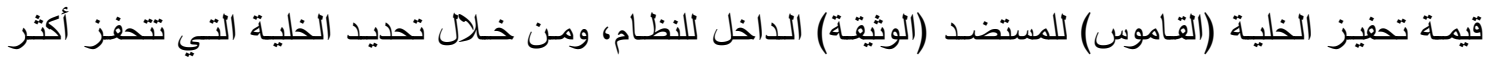

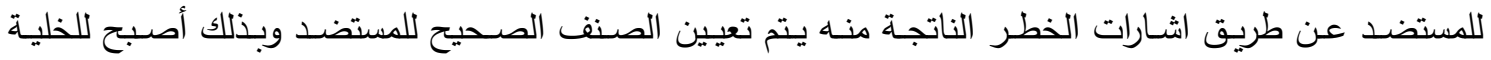
التغصنية قابلية تعيين الصنف بالتحديد. يتضمن الجدول (5) مقاييس (TP , FP , TN , FN) لوثائق الاختبار (40) وثيقة لـ (250) خاصية. 
جدول (5) مقاييس (TP , FP , TN , FN) لوثائق الاختبار

\begin{tabular}{|c|c|c|c|c|}
\hline Model & TP\% & FP\% & TN\% & FN\% \\
\hline DCM & 90 & 0 & 100 & 10 \\
\hline NB & 90 & 10 & 90 & 10 \\
\hline
\end{tabular}

يتضمن الجدول (6) عدة مقاييس لتصنيف وثائق الاختبار بالاعتماد على قيم جدول (4).

جدول (6) عدة مقاييس لتصنيف وثائق الاختبار

\begin{tabular}{|c|c|c|c|c|c|c|}
\hline Measure & Precision & Recall & Specificity & F1-macro & \multicolumn{2}{|c|}{ F1-micro } \\
\hline DCM & 100 & 90 & 100 & 95 & 94.74 & 95.25 \\
\hline NB & 90 & 90 & 90 & 90 & 90 & 90 \\
\hline
\end{tabular}

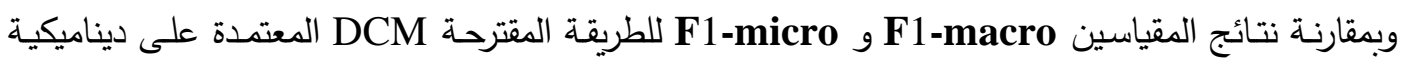
عمل النظام المناعي الفطري مع نتائج الطرائق السابقة الموضحة بالجدول (7) يتبين أن أنموذج DCM أفضل من الطرائق السابقة.

جدول(7) مقارنة نتائج دقة مصنفات مختلفة لمقياسي F1-macro و F1-micro

\begin{tabular}{|c|c|c|c|c|}
\hline $\begin{array}{l}\text { Results reported } \\
\text { by }\end{array}$ & Dataset & $\begin{array}{l}\text { Classifier } \\
\text { Used }\end{array}$ & F1-Micro & F1-Macro \\
\hline $\begin{array}{c}\text { [Tan et al., 2005] } \\
{[36]}\end{array}$ & 20 Newsgroup & Centroid & 0.8420 & .8380 \\
\hline \multirow{2}{*}{$\begin{array}{c}\text { [Qian et al., } \\
\text { 2007] } \\
{[34]}\end{array}$} & \multirow[b]{2}{*}{ Reuters 21578} & $\begin{array}{l}\text { Decision } \\
\text { Tree }\end{array}$ & 0.884 & 0.822 \\
\hline & & Linear SVM & 0.920 & 0.871 \\
\hline \multirow{4}{*}{$\begin{array}{c}\text { [Lan et al., 2009] } \\
{[25]}\end{array}$} & \multirow{2}{*}{ Reuters 21578} & SVM & 0.921 & 0.900 \\
\hline & & K-NN & 0.840 & 0.825 \\
\hline & \multirow{2}{*}{20 Newsgroup } & SVM & 0.808 & 0.808 \\
\hline & & K-NN & 0.691 & 0.691 \\
\hline \multirow{2}{*}{$\begin{array}{c}\text { Nada and Rasha] } \\
{[} \\
2012 \\
\end{array}$} & \multirow{2}{*}{$\begin{array}{c}\text { Software } \\
\text { Engineering } \\
\text { Documents }\end{array}$} & DCM & 0.95 & 0.95 \\
\hline & & NB & 0.90 & 0.90 \\
\hline
\end{tabular}

يعد الوقت المستغرق للتدريب والتصنيف من العوامل المهمـة ومن الثكل (15) يتبين أن الوقت يتتاسب

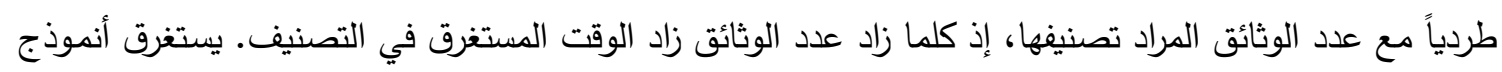

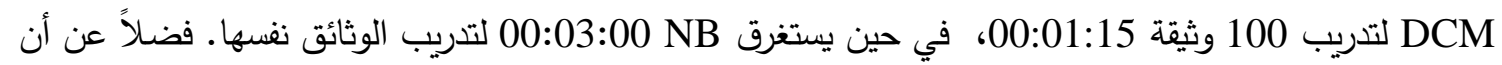
هيكلية وثائق هندسة البرمجيات تختلف عن وثائق الانترنيت، إذ تتكون وثيقة SWE من عدة صفحات لذا تستغرق وقت أطول من وثائق الانترنيت في التدربب والتصنيف، إذ عند تدريب المصنف DCM على 400 وثيقة انترنيت

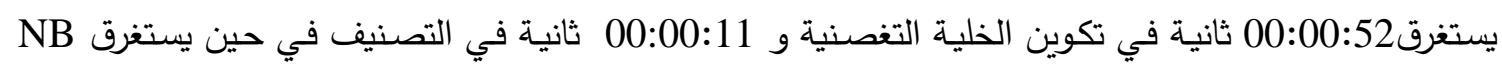
00:01:00 دقيقة في التدريب و50:00:00:00 ثانية في التصنيف. 


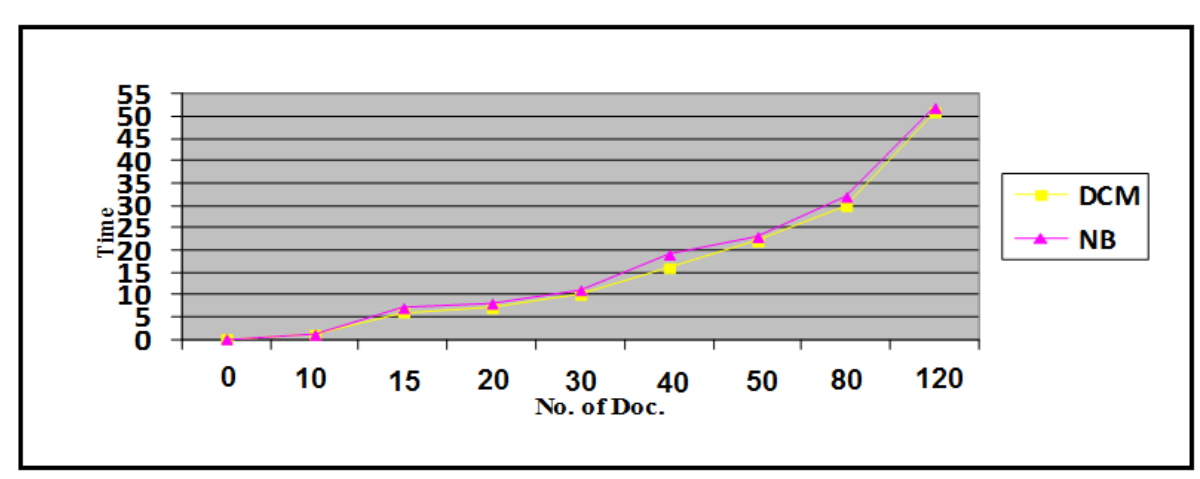

الثكل (15) علاقة الوثائق مع الوقت المستغرق لتصنيفها

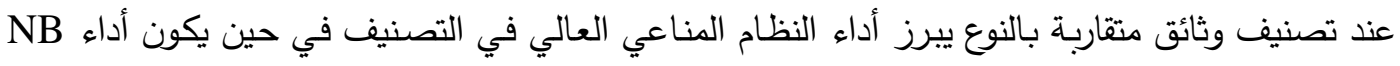
أقل لكونه يعتمد على الاحتماليات و تزداد دقة NB في الاصناف المتباعدة.

\section{Conclusions} الاستنتاجات

من خـال تطبيق انموذج DCM في البحث لغرض تصنيف وثائق هندسة البرمجيات وعلى وفق النتائج التي تم الحصول عليها، تم التوصل إلى الاستتناجات الآتية:بعد دراسـة بعض تقنيات النظام المناعي AIS تم اختيار تقنية الخطر والخلية التغصنية DC لحل المشكلة المدروسة لما لهذه التقنية من مميزات تساعد في عملية التصنيف. بعد ملاحظة نتائج البحث التي تم الحصول عليها تم التوصل الى جدارة التطرق إلى الموضوع الذكائي

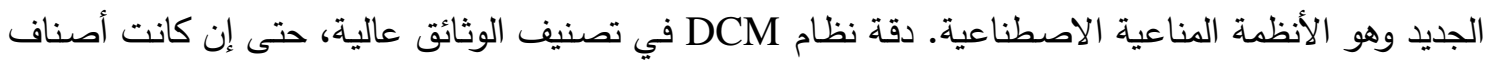

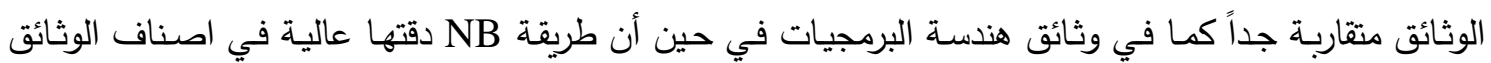

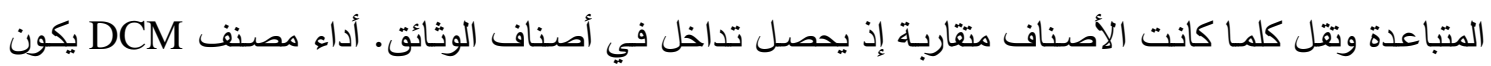

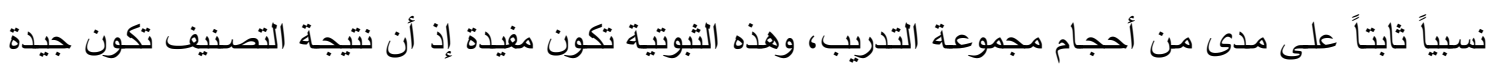
باستخدام مجموعة تدريب صغيرة الحجم وهذا ينفع المستخدمين من تدريب النظام على عدد قليل من الوثائق وفي مني الوقت نفسه يمتلك تتبؤات دقيقة. يمتلك النظام المناعي بصورة عامة القابلية على تكوين مصنفات ذات دقة تتبؤ أفضل باستخدام متجهات خواص ذات حجم أقل من متجهات خواص NB. ان اختيار المصنف لا يعتمد فقط على لئ دقة التتبؤ المكن أن يحققها، ولكن أيضاً على حجم الوقت المستغرق في التدريب، إذ أن المستخدم لا يرغب في

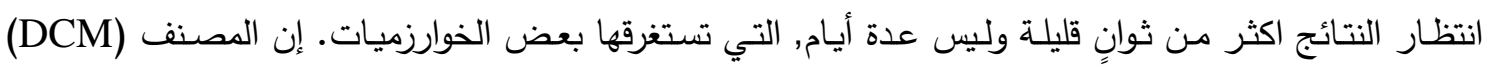
المبني على تقنية عمل النظام المناعي الفطري يحقق دقة تتبؤ جيدة وفي وقت قليل جداً يسمح باستخدامه في مشاكل العالم الحقيقي. 


\section{المصاد}

[1] Balthrop, J., Esponda, F., Forrest, S., and Glickman, M., (2002), "Coverage and generalization in an artificial immune system", In Proc. of the Genetic and Evolutionary Computation Conference (GECCO), pp.3-10.

[2] Brownlee, J., (2008), "Clonal Selection as an Inspiration for Adaptive and Distributed Information Processing", $\mathrm{PhD}$ thesis, Swinburne University, Melbourne, Australia.

[3] Cohen, W., Singer, Y., (1999), "Context sensitive learning methods for text categorization", ACM Transactions on Information Systems, vol. 17, no. 2, pp. 141- 73 .

[4] Danziger, M., Delima Neto, F., Laerda, M.(2009), " Danger theory and Multi agents Applied for Addressing the Deny of Service Detection Problem in IEEE 802.11 Networks, university of pernambuco, Brazil, in ninth international conference on intelligent system design and applications ISDA, Pisa, Italy, 695702, IEEE computer society.

[5] De Castro, L. N., Timmis, J., (2002). "Artificial Immune Systems: A New Computational Intelligence Approach", ISBN 1-85233-594-7, Springer, England.

[6] De Castro L.N., Von Zuben, F.J., (2002), "Learning and optimization using the clonal selection principle", IEEE Trans. Evol. Comput., vol. 6, no. 3, pp 239251.

[7] Engelbrecht, Andries, P., (2007), "Computational Intelligence: An Introduction", 2nd edition, University of Pretoria, South Africa, John Wiley \& Sons Ltd.

[8] Forman, George, Eshgi, Kave, Chiocchetti, (2005), "Finding Similar Files in Large Document Repositories", Proc. 11th ACM International Conf. on Knowledge Discovery and Data Mining (KDD'05), 21-25, Chicago, Illinois, USA

[9] Fouad, Walid, A., Badr, Amr, A., Abdel- Rahman, Ebrahim, F., (2007), "A compartive Study of web document classification approaches", Proc. 37th International Conf. on computers and industrial Engineering, pp. 197-206, Alexandria, Egypt.

[10] Goldsby, Richard, A., Kindt, Thomas, J., Osborne, Barbara, A, Kuby, J., (2003), " Immunology", 5th Edition, W. H. Freeman and Company.

[11] Greensmith J., Aickelin, U., (2007),"Dendritic cells for synscan detection", Proc. of the Genetic and Evolutionary Computation Conf. (GECCO ),pp. 49-56.

[12] Greensmith J., Aickelin, U., (2008), "The deterministic dendritic cell algorithm", Proc. of the 7th International Conf. on Artificial Immune Systems (ICARIS), pp. 291-302. Springer.

[13] Greensmith, J. , (2007),"The Dendritic Cell Algorithm", PhD thesis, University of Nottingham.

[14] Greensmith, J., Aickelin, U., (2009), "Artificial Dendritic Cells: Multi-faceted Perspectives", in Human-centric information processing through granular modeling, studies in computational intelligence (182). Springer, Berlin, pp 373395, ISBN 9783540929154. 
[15] Greensmith, J., Aickelin, U. and Cayzer, S., (2008), "Detecting Danger: The Dendritic Cell Algorithm", to appear in 'Robust Intelligent Systems' edited book.

[16] Gu, F., Greensmith J., Aickelin, U., 2008," Further Exploration of the Dendritic Cell Algorithm: Antigen Multiplier and TimeWindows",Proc. of 7th International Conf. on Artificial Immune Systems (ICARIS ), Phuket, Thailand, pp. 142-153.

[17] Hotho, A., Nurnberger, A., PaaB, G., (2005), " A Brief survey of Text Mining", Journal for Computational Linguistics and Language Technology, Vol 20, pp. 1962.

[18] Iqbal, A., (2006), "Danger Theory Metaphor In Artificial Immune System For System Call Data", PhD theises, Universiti Teknologi Malaysia.

[19] Ismail, Nabil, A., Abdul-Kader, H., Al-Sheshtawi, Khaled, A.,(2010), "Artificial Immune Clonal Selection Classification Algorithms for Classifying Malware and Benign Processes Using API Call Sequences", IJCSNS International Journal of Computer Science and Network Security, VOL.10 No.4, pp.31-39.

[20] Janeway, C., (2004), Immunobiology, Garland Science, 4th Edition.

[21] Joachims, T., (1998), " Text categorization with support vector machines: Learning with many relevant features". Proc. Of European Conf. on Machine Learning (ECML), Vol 1398, pp. 137-142.

[22] Kamthan,P., (2007), "On the Prospects and Concerns of Integrating Open Source Software Environment in Software Engineering Education", Concordia University, Montreal, Quebec, Canada, Journal of Information Technology Education Volume 6.

[23] Khelil, H., Benyettou, A.,(2006), Artificial Immune Systems For Illnesses D Diagnostic, Ubiquitous Computing and Communication Journal, Algeria.

[24] Kuby, J., (1997), "Immunology", 3rd Ed., W. H. Freeman and Co.

[25] Lan, M., Tan, C. L., Su. J., and Lu, Y.2009. Supervised and Traditional Term Weighting Methods for Automatic Text Categorization. IEEE Transactions on Pattern Analysis and Machine Intelligence, Volume: 31 (4), pp. 721 - 735.

[26] Lutz, M., Schuler, G., (2002), "Immature, semi-mature, and fully mature dendritics -cells: which signals induce tolerance or immunity?", In Trends in immunology, Vol 23, Issue9 Elsevier, pp. 445-449.

[27] Matzinger, P., (1994), "Tolerance, danger and the extended family", Annual Reviews in Immunology, 12:991-1045.

[28] Mitchell, T., (1997), "Machine Learning". McGraw Hill, New York.

[29] Mohammad, A., (2008), "Support Vector Machine Text Classification for Arabic Articles: Ant Colony Optimization Based Feature Subset Selection", PhD thesis, Arabic Academy for Banking and Financial Sciences, Amman, Jordan.

[30] Nanda, Satyasai, J., (2009), "Artificial Immune Systems: Principle, Algorithms And Applications", MSC thesis, Thapar University, India.

[31] Özgür, A., (2004), "Supervised and Unsupervised Machine Learning Techniques For Text Document Categorization", MSC thesis, , Bo gazici University. 
[32] Pazzani, M., Billsus, D., (1997), "Learning and revising user profiles: the identification of interesting web site ", machine learning, pp. 313-331.

[33] Romero, A., Niño, F., (2007), "An Artificial Immune System Based on Information Theory for Keyword Extraction from Text Documents", Revista Avances en Sistemas e Informática, Vol.4 No. 2, pp. 25-32, Edición Especial: II Congreso Colombiano de Computación - CCC.

[34] Qian, T., Xiong, H., Wang, Y., and Chen, E. 2007. On the strength of hyperclique patterns for text categorization. An International Journal Information Sciences, Vol. 177, pp. 4040-4058.

[35] Sebastiani, F., (2002), "Machine Learning in Automated Text Categorization", ACM Computing Surveys, vol. 34, no. 1, pp. 1-47.

[36] Songbo, T., Cheng, X., Ghanem, M. M., Wnag, B., and Xu, H. 2005. A novel refinement approach for text categorization. In the Proceedings of Fourteenth ACM International Conference on Information and Knowledge Management, pp $469-476$.

[37] Tan, S., (2008), "An improved centroid classifier for text categorization". Journal of Expert System with Applications, Vol 35, pp 279 - 285.

[38] Twycross, Jamie, P., (2007)," Integrated Innate And Adaptive Artificial Immune System Applied To Process Anomaly Detection", PhD theises, University of Nottingham, UK.

[39] Wei , T., (2010), "Homology Modeling of Toll-Like Receptor Ligand-Binding Domains: A Leucine-Rich Repeat Assembly Approach",PhD theises, LudwigMaximilians-Universität München.

[40] Williams, C., Harry, R., and McLeod, J. (2007), "Mechanisms of apoptosis induced DC suppression", Journal of Immunology, 120S158. 